\title{
Nonlinear structural response in jet fire in association with the interaction between fire loads and time-variant geometry and material properties
}

\author{
Sang Jin Kim ${ }^{\mathrm{a}}$, Jin Lee ${ }^{\mathrm{b}}$, Sang Hwan Kim ${ }^{\mathrm{b}}$, Jung Kwan Seo ${ }^{\mathrm{a}}$, Bong Ju Kim ${ }^{\mathrm{a}}$, Yeon Chul Ha ${ }^{\mathrm{a}}$ \\ Jeom Kee Paik ${ }^{\mathrm{a}, \mathrm{b}, \mathrm{c},{ }^{*}}$, Kang Su Lee ${ }^{\mathrm{d}}$, Byoungjae Park ${ }^{\mathrm{d}}$, Min Suk Ki ${ }^{\mathrm{d}}$ and Jung Min Sohn ${ }^{\mathrm{e}}$ \\ ${ }^{a}$ The Korea Ship and Offshore Research Institute (The Lloyd's Register Foundation Research \\ Centre of Excellence), Pusan National University, Busan, Korea \\ ${ }^{\mathrm{b}}$ Department of Naval Architecture and Ocean Engineering, Pusan National University, Busan, \\ Korea \\ ${ }^{c}$ Department of Mechanical Engineering, University College London, London, UK \\ ${ }^{\mathrm{d}}$ Korea Research Institute of Ships and Ocean Engineering, Daejeon, Korea \\ ${ }^{\mathrm{e}}$ Department of Naval Architecture and Marine Systems Engineering, Pukyoung National \\ University, Busan, Korea
}

\begin{abstract}
For safety design of structures against fire loads, time-variant geometry and material properties depending on the temperature should be considered with fluid-structure interaction (FSI) analysis. One-way FSI analysis is generally applied due to a time consuming task. But, it has big difference of structural response between conducting one-way and two-way FSI analysis. And two-way analysis is also affected by time increment of analysis for updating the geometry, and fire loads. The aim of this study is to investigate the effect of time increments on two-way FSI analysis of structures subjected to jet fire, and to suggest a proper time increment for two-way FSI analysis. In the present study, geometries and material properties are updated at every time increments, and kinds of two-way FSI analysis are performed with different time increments by using computational fluid dynamics (CFD) and nonlinear finite element analysis (NLFEA) and an interface program between CFD and NLFEA.
\end{abstract}

\section{Keywords}

* Corresponding author. Tel.: +82515102429

Email address: jeompaik@pusan.ac.kr 
Fire loads, time-variant geometry and material properties, structural response, two-way FSI analysis, time increments

\section{Introduction}

Oil and gas are important sources of energy, produced mainly in demanding oceanic and industrial environments with significant fire and explosion hazards. The topsides of offshore platforms are the most likely structures to be exposed to hazards such as hydrocarbon fire and/or explosion (Czujko and Paik, 2012a; 2012b). A number of major accidents involving the topsides of offshore installations have been reported, such as the Piper Alpha accident of July 6, 1988 in the North Sea and the Deepwater Horizon accident of April 20, 2010 in the Gulf of Mexico, as shown in Fig. 1 (Vinnem, 2007; USCG, 2011).

After the Piper Alpha accident, greater attention was focused on the structural design of offshore rigs to counter the threat of fires and determine the means of minimizing damage from accidents. The Deepwater Horizon accident reconfirmed the importance of structural design to resist hydrocarbon fires.

Structural design and safety assessment both require the identification of the characteristic actions and action effects of fire. The thermal characteristics of steel are the main factors affecting structural integrity in fire. The specific heat of steel varies with temperature, as shown in Fig. 2(a). At temperatures above $400^{\circ} \mathrm{C}$ the mechanical properties of steel significantly decrease, as shown in Fig. 2(b) which represents a non-continuous segment plot based on the definition of Eurocode (EN, 2005). The heat from fire flows relatively 'rapidly' in steel, which is a good heat conductor compared to other materials, e.g., concrete. Thus, fire can lead to the collapse of steel structures, and the severity of fire loads usually requires an application of passive fire protection (PFP) for critical structural elements. So, the characteristics of change in the material property should be considered, when analyzing the structural response subjected to fire loads.

In industry practices, simplified methods are usually applied for investigations of structural responses to fire on offshore installations, according to the structural designer's and/or engineer's convenience 
(UKOOA and HSE, 2003; API, 2006; EN, 2005; NORSOK, 2008). Some of the ways that such analyses may be simplified include the following:

- Simplification of load: Idealized fire loads

- Simplification of structure: 1-dimensional structure

- Simplification of procedure: Numerical calculation

The conventional fire safety design approaches are essentially composed of a series of regulations, standards and procedures. As a result, the conventional approaches need to be supplemented by integrated fire safety design approaches that are in principle based on performance. Integrated fire safety design requires taking advantage of fire computational fluid dynamics (CFD) simulations (Paik et al., 2010, Salem, 2010) and nonlinear structural response analyses (Guedes Soares et al., 1998; Shetty et al., 1998; Guedes Soares and Teixeira, 2000; Skallerund and Amdahl, 2002; Paik and Thayamballi, 2007).

The action characteristics of hydrocarbon fires can be modelled using CFD, which is recognized as one of the most powerful modelling approaches currently available. CFD makes it possible to model fire using first principles through solving the basic conservation equations of mass, energy, and momentum and using accurate 3D topological models of structures. This field or CFD modelling approach has successfully solved various fire safety problems (Novozhilov, 2001).

In addition, the action effects of fire on structures can be characterized by the nonlinear finite element method (NLFEM). Therefore, more refined methods for modelling CFD and NLFEM simulations will help improve the prediction of the fire risk associated with offshore installations (Kim, 2014). Generally, structural analysis is performed after CFD fire simulation as named one-way simulation due to time and technical issues. However, it is needed to consider interaction between fire and structure for obtaining more accurate structural response.

The aims of this study are i) to perform a fluid-structure interaction (FSI) analysis of structures on platforms under jet fire through one-way and two-way analyses, ii) to compare the results of these 
analyses depending on the time increment in two-way analysis, and iii) to propose a proper time increment for two-way FSI analysis.

\section{A procedure for nonlinear response analysis in fire}

The structural response analysis in fire is performed after obtaining the fire loads such as gas cloud temperature, heat flux, radiation etc. Fig. 3 illustrates a scheme of one-way FSI method of analyzing the nonlinear structural response subjected to fires.

For the nonlinear structural response analysis with a two-way method, it is necessary to consider updates of the time-variant geometry and material properties. Fig. 4 illustrates a scheme of two-way FSI analysis. The structural response assessment becomes more accurate with smaller time increments used in two-way analysis, and this process requires the use of a proper time increment $(\Delta t)$. If the time increment is the same as the total simulation time, then the process is a one-way FSI analysis.

Fig. 5 shows a procedure for a two-way FSI analysis of nonlinear structural responses under fire proposed in this study. This procedure involved the following steps;

- Fire CFD simulation by time increment (which can be set as $0.1 \mathrm{~s}, 1 \mathrm{~s}$, or another increment)

- Heat transfer analysis and nonlinear FEA, with results by CFD simulated until the first time increment

- Fire CFD simulation, with updated geometry results by FEA until the second time increment

- Heat transfer analysis and nonlinear FEA, with results by CFD simulation until the second time increment

- Repetition of CFD simulation, FEA and update of geometry

In the present study, KFX for CFD simulation, KFX2DYNA for estimating the transference of thermal loads from KFX to structures in FEM, and LS-DYNA for the nonlinear structural analysis are applied. 


\section{Validation of FSI modelling technique}

Paik et al. (2013) developed a modelling technique for nonlinear structural response under fire with CFD, NLFEM, and interface between CFD and NLFEM, and it is validated with an experimental test result by Cong et al. (2005).

Fig. 6 and Table 1 show the details of target I-girder and applied loads in the experimental test and validation of modelling technique.

For the boundary conditions, simply supported conditions are applied at the centers of the webs at both ends $\left(U_{x}, U_{y}, U_{z}, R_{x}, R_{z}=\right.$ fixed at left end, and $U_{y}, U_{z}, R_{x}, R_{z}=$ fixed at right end). In addition, the cross sections at both ends remain in-plane.

In the heat transfer analysis, the emissivity of gas and steel, and the heat conductivity of the steel affect the calculation of steel temperature. These measurements should be obtained from experimental tests, because the coefficients are dependent on factors such as the specific material, roughness and geometry.

Case studies with kinds of emissivity and heat conductivity are performed and compared. Finally, the values of 0.24 for emissivity of steel, and 16.4 for heat conductivity are applied.

Figs. 7 and 8 compare the steel temperature and deflection by the test and structural analysis. In Fig. 7 , gas cloud temperatures by EN (1991) and ISO (2014) are shown for information. The modelling technique developed by Paik et al. (2013) is adopted in FSI analysis of structures in next chapter.

\section{Structural response of structure by Two-way FSI analysis}

\subsection{Target structure}

I-girder type of beam is one of primary members which compose the offshore platform, and simple structure can avoid effects of others such as geometry, connections, etc. So, I-girder described in Chapter 
3 is selected as the target structure to investigate the effect of two-way FSI analysis and time increments.

Fig. 9 presents the details of target structure and boundary conditions for FSI analysis subjected to jet fire.

\subsection{FSI analysis of I-girder subjected to jet fire}

\subsubsection{CFD simulation for structure subjected to jet fire}

Kameleon FireEX (KFX, 2015) CFD tool is used to jet fire simulation. For the fire simulation using $\mathrm{KFX}$, it is necessary to select a jet fire scenario. In this study, a jet fire with a $0.04 \mathrm{~kg} / \mathrm{s}$ leak rate and a duration of $3600 \mathrm{~s}$ is applied as follows:

- Leak rate: $0.04 \mathrm{~kg} / \mathrm{s}$

- Leak hole size: $30 \mathrm{~mm}$

- Leak duration: $3600 \mathrm{~s}$

- Leak direction: $+\mathrm{Z}$

- Leak position in $X$ direction: $2.1 \mathrm{~m}$

- Leak position in $\mathrm{Y}$ direction: $0.0 \mathrm{~m}$

- $\quad$ Leak position in $\mathrm{Z}$ direction: $-1.0 \mathrm{~m}$

Fig. 10 shows the extent of analysis for the fire CFD simulations and the position of the leak in KFX. In the cases of jet fire, the fire loads, including the factors of temperature and heat flux, tend to go up. Therefore, the extent of the fire in the Z-direction is wider that in the other directions.

Fig. 11 illustrates the location of the monitoring points at nine sections. The fire loads for heat transfer analysis are obtained at these points. Similar sets of points are also located in FEA for investigation of the structural response.

\subsubsection{Transference of thermal loads to structure}

Paik et al. (2013) developed an interface program between KFX and LS-DYNA for transferring fire loads as named KFX2DYNA (2013). The program interpolates the related information at the nearest monitoring points before exporting it to LS-DYNA for the heat transfer analysis. LS-DYNA uses plate- 
shell elements to model the structures, and takes both radiation and convection into account (Paik et al., 2013).

For the heat transfer analysis, the changes of specific heat and the thermal conductivity of the material are considered, depending on the temperatures, as shown in Fig. 12. These analyses are performed at every time increment to detect the transference of thermal loads.

In addition, it is necessary to define the time increment $(\Delta t)$ for the two-way FSI. In this study, five time increments are considered for investigating the effects of measuring with different time increments. The time increments are determined to be $60,30,15,10$, and $10+\alpha$ (min.), as follows:

- Case I: $3600 \mathrm{~s}$

- $\quad$ Case II: $1200 \mathrm{~s}$

- $\quad$ Case III: $900 \mathrm{~s}$

- Case IV: $600 \mathrm{~s}$

- Case V: $600 \mathrm{~s}$ until $2400 \mathrm{~s}$, and $400 \mathrm{~s}$ from $2400 \mathrm{~s}$ to $3600 \mathrm{~s}$

Case I, with a time increment of $3600 \mathrm{~s}$, can be treated as equal to a one-way FSI analysis, because its total simulation time is $3600 \mathrm{~s}$.

\subsubsection{Structural analysis}

The nonlinear structural response analysis with the modelling technique validated in Chapter 3 , is performed by using LS-DYNA (2015). All of the structural members are made of mild steel, with 235 MPa of yield stress and 205,800 MPa of Young's modulus. An elastic perfectly plastic material model is applied, and the changes of material properties (as presented in Fig. 2) and heat conductivity are considered.

\subsection{Results of analysis}


Figs. 13-15 show the results of the FSI analyses, including the CFD simulations, heat transfer analyses and the nonlinear FEA at section E, which is the mid-section presented in Fig. 11. The results from the other sections are presented in Appendix A.

Fig. 13 presents the gas cloud temperature-time histories in the KFX fire CFD simulation, according to different time increments. It shows that the gas cloud temperatures decrease along with decreases in the time increment $(\Delta t)$. This decease results from the fact that the temperature at the heat source is lower than that at the end of the flame.

Fig. 14 illustrates the steel temperature-time histories by heat transfer analysis, and Fig. 15 shows the nonlinear structural response, which indicates the deflection at the center of the I-girder versus the time histories by LS-DYNA nonlinear FEA, according to changes in the time increments.

In Fig. 15, it seems that there are large differences in structural response according to the time increments. These differences signify that the two-way FSI analyses should be performed with finer and finer time increments as the temperature increases.

Fig. 16 illustrates the maximum structural responses, which are deflections at $3600 \mathrm{~s}$ versus the time increments of the two-way FSI analysis for deciding the converged time increment. In this study, the time increments of 15 min. (Case III) or $15+\alpha$ min. (Case V) are considered the most suitable time increments for FSI analysis of the I-girder subjected to jet fire. Specifically, finer time increments should be applied as the structure losses its strength with higher steel temperatures.

Fig. 17 shows the deformed shapes as projected by the nonlinear structural analysis of the I-girder in jet fire at $3600 \mathrm{~s}$.

\section{Conclusion and further studies}

The objectives of this study have been to investigate the interactions between the fire loads, timevariant geometry and the material properties in jet fires, and the effect of time increments in two-way FSI analysis. Based on the results, the following conclusions and further studies can be drawn. 
- In such non-uniform cases, two-way method can be applied to take account of the various interacting effects.

- For a structure in the jet fire, 15 min of time increment can be proper for the two-way method analysis. And it has similar structural behavior to finer time increment.

- The one-way method analysis tends to overestimate structural consequences compared to the twoway method analysis, as the two-way method is a more refined approach. The one-way method's tendency to overestimate is partly an effect of its inability to allow for the readjustment of fire load characteristics due to changes in time-variant geometry as the structure is subjected to more severe fire load conditions.

- As the structural consequences grow more severe with time, the differences between the one-way and multi-way methods become more significant.

- The one-way method for safety assessment and design may result in a pessimistic tendency to overestimate the safety requirements.

In further studies, the effect of time increment of FSI analysis considering pool fire and large structure will be investigated.

\section{Acknowledgement}

\section{References}

API, 2006. Recommended practice for the design of offshore facilities against fire and blast loading, API RP 2FB. American Petroleum Institute, WA, USA.

Cong S., Liang S. and Dong Y., 2005. Experimental investigation of behavior of simply supported steel beams under fire. Journal of Southeast University (Natural Science edition) 35, 66-68 (in Chinese). 
Czujko J. and Paik J.K., 2012a. Hydrocarbon explosion and fire engineering - assessing and managing hydrocarbon explosion and fire risks in offshore installations. Marine Technology, The Society of Naval Architects and Marine Engineers 23-25.

Czujko J. and Paik J.K., 2012b. Paradigm change in safety design against hydrocarbon explosions and fires. Fire and Blast Information Group Newsletter (60), 20-38.

EN, 1991, Actions on structures - part 1-2: general actions - actions on structures exposed to fire, Eurocode 1. European Standard, Brussels, Belgium.

EN, 2005. Design of steel structures - part 1-2: general rules - structural fire design, Eurocode 3. European Standard, Brussels, Belgium.

Guedes Soares C., Gordo J.M. and Teixeira A.P., 1998. Elasto-plastic behaviour of plates subjected to heat loads. Journal of Constructional Steel Research 45(2), 179-198.

Guedes Soares C. and Teixeira A. P., 2000. Strength of plates subjected to localized heat loads. Journal of Constructional Steel Research 53, 335-358.

ISO, 2014. Fire resistance tests - elements of building construction - part 11: specific requirements for the assessment of fire protection to structural steel elements, ISO 834-11:2014. International Standards Organization, Geneva, Switzerland.

KFX, 2015. User's manual for Kameleon FireEx 2010. Computational Industry Technologies AS, Stavanger, Norway.

KFX2DYNA, 2013. User's manual for and interface program between KFX and ANSYS/LS-DYNA codes. The Korea Ship and Offshore Research Institute, Pusan National University, Busan, Korea.

Kim J.H., 2014, A new procedure for fire structural assessment of offshore installations, Ph.D. thesis, Pusan National University, Busan, Korea.

LS-DYNA, 2015. User's manual for ANSYS/LS-DYNA version 14.5. ANSYS Inc., PA, USA.

NORSOK, 2008. Technical safety, NORSOK S-001. Norwegian Standard, Lysaker, Norway. 
Novozhilov V., 2001. Computational fluid dynamics modeling of compartment fires. Progress in Energy and Combustion Science 27, 611-666.

Paik J.K., Czujko J., Kim J.H., Park S.I., Islam S., Lee D.H., 2013. A new procedure for the nonlinear structural response analysis of offshore installations in fires. Transactions of the Society of Naval Architects and Marine Engineers 121, 224-250.

Paik J.K., Kim B.J., Jeong J.S., Kim S.H., Jang Y.S., Kim G.S., Woo J.H., Kim Y.S., Chun M.J., Shin Y.S. and Czujko J., 2010. CFD simulations of gas explosion and fire actions. Ships and Offshore Structures 5(1), 3-12.

Paik J.K. and Thayamballi A.K., 2007. Ship-shaped offshore installations: design, building, and operation. Cambridge University Press, Cambridge, UK.

Salem A., 2010. Fire engineering tools used in consequence analysis. Ships and Offshore Structures 5(2), 155-187.

Shetty N.K., Guedes Soares C., Thoft-Christensen P. and Jensen F.M., 1998. Fire safety assessment and optimal design of passive fire protection for offshore structures. Reliability Engineering and System Safety (61), 139-149.

Skallerund B. and Amdahl J., 2002. Nonlinear analysis of offshore structures. Research Studies Press, Hertfordshire, UK.

UKOOA and HSE, 2003. Fire and explosion guidance, Issue 1. United Kingdom Offshore Operators Association, and Health and Safety Executive, London, UK

USCG, 2011. Report of investigation into the circumstances surrounding the explosion, fire, sinking and loss of eleven crew members aboard the mobile offshore drilling unit: Deepwater Horizon. United States Coast Guard, ME, USA.

Vinnem J.E., 2007. Offshore risk assessment - principles, modelling and application of QRA studies. Springer, Stavanger, Norway. 
$12 / 27$ 


\section{Tables and Figures}

Table 1 Dimensions of the structure and locations of monitoring points at mid-section.

\begin{tabular}{|c|c|c|}
\hline \multirow{2}{*}{\begin{tabular}{|c|c|}
\hline \\
\cline { 2 - 3 }
\end{tabular}} & $\mathrm{h}_{\mathrm{w}}(\mathrm{mm})$ & 250 \\
\cline { 2 - 3 } & $\mathrm{b}_{\mathrm{f}}(\mathrm{mm})$ & 125 \\
\hline & $\mathrm{t}_{\mathrm{w}}(\mathrm{mm})$ & 6 \\
\hline
\end{tabular}

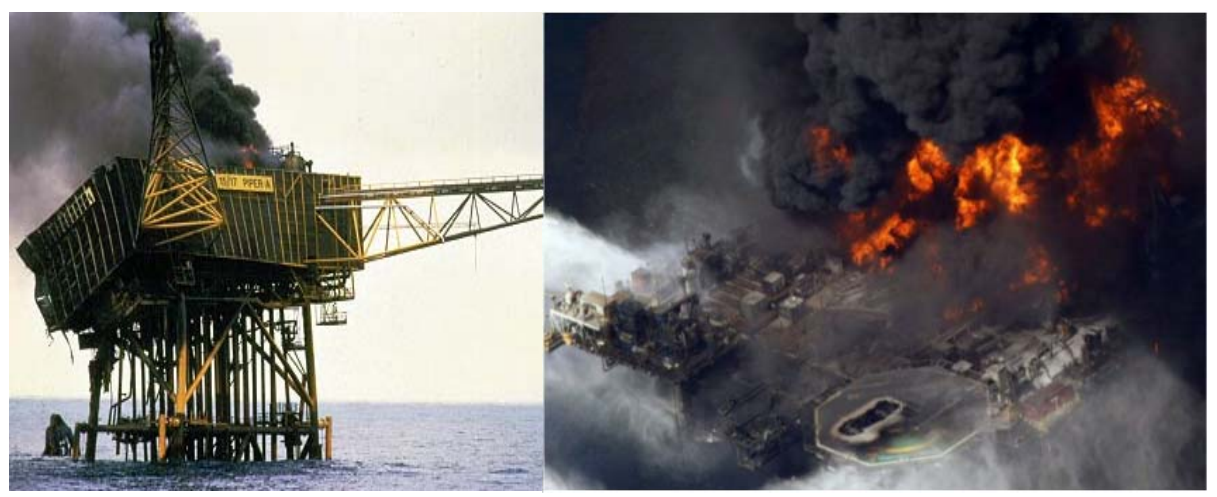

Fig. 1. The Piper Alpha (left) and Deepwater Horizon (right) accidents.

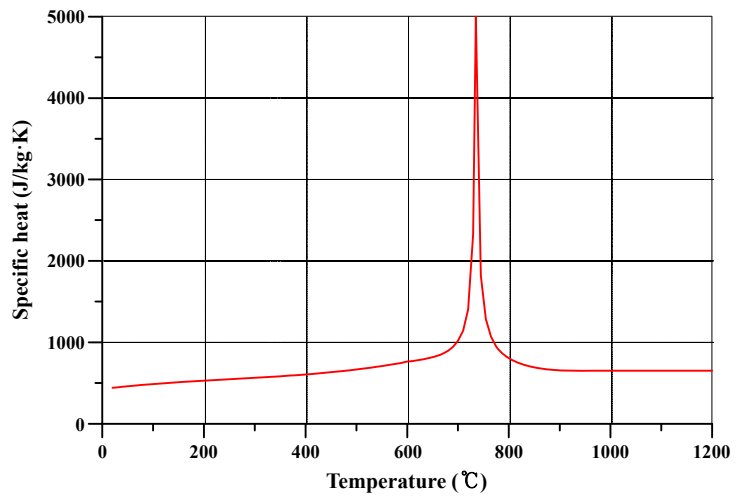

(a) Specific heat of steel

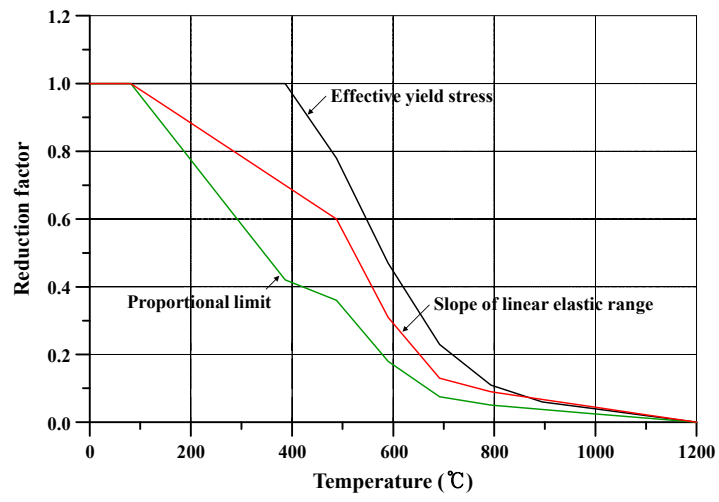

(b) Mechanical properties of steel

Fig. 2. Examples of the change of material properties according to temperature (EN 2005).

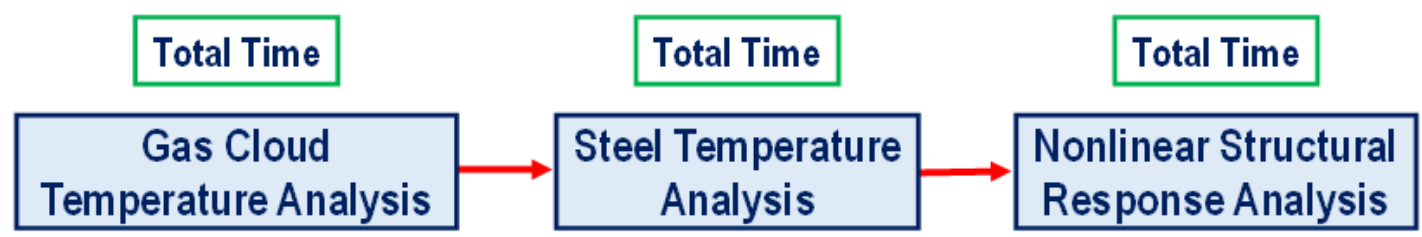

Fig. 3. A scheme of one-way method for analysis of nonlinear structural response to fires. 


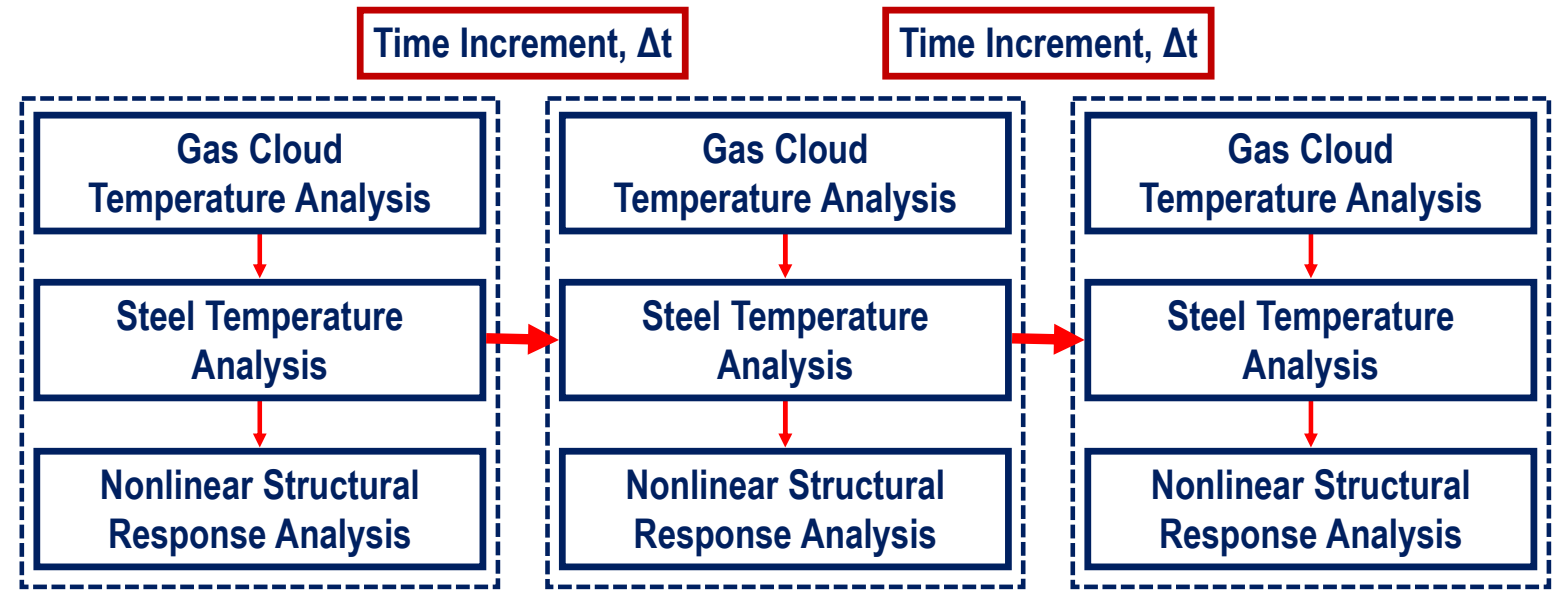

Fig. 4. A scheme of two-way FSI analysis, with a time increment of $\Delta t$.

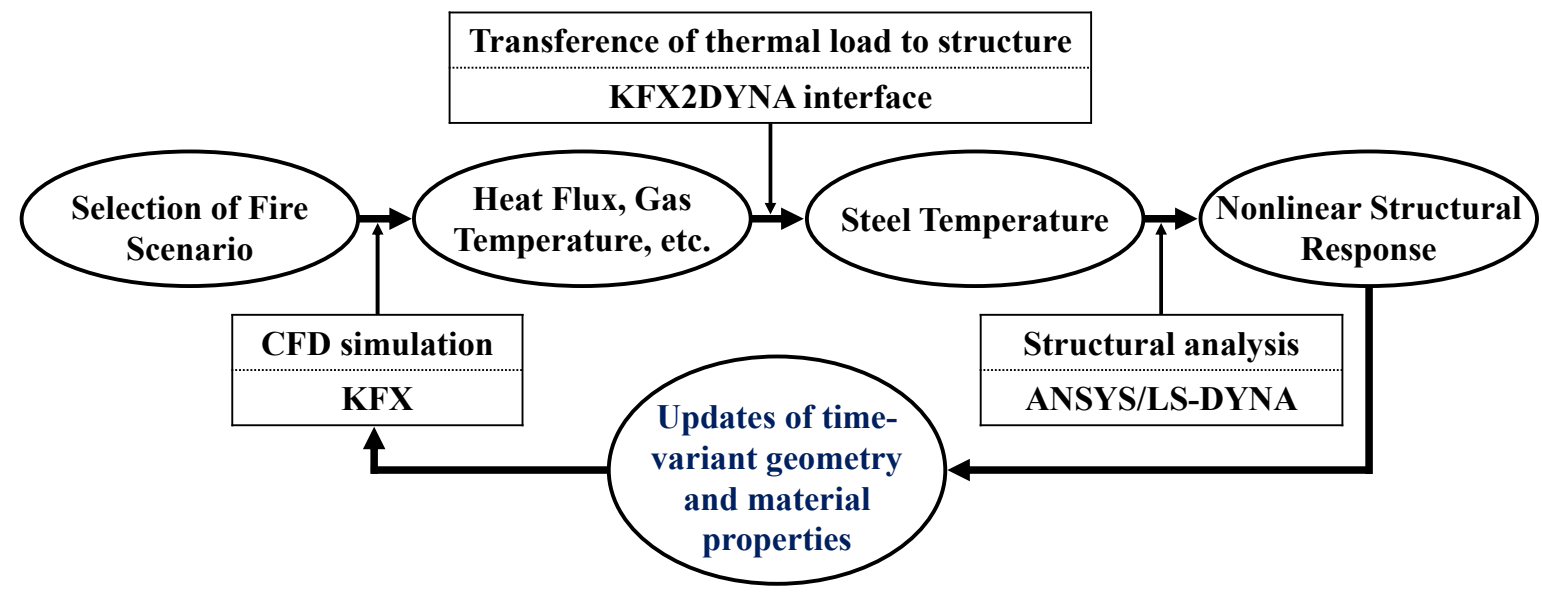

Fig. 5. Procedure for a two-way method of analyzing nonlinear structural response subjected to fires.

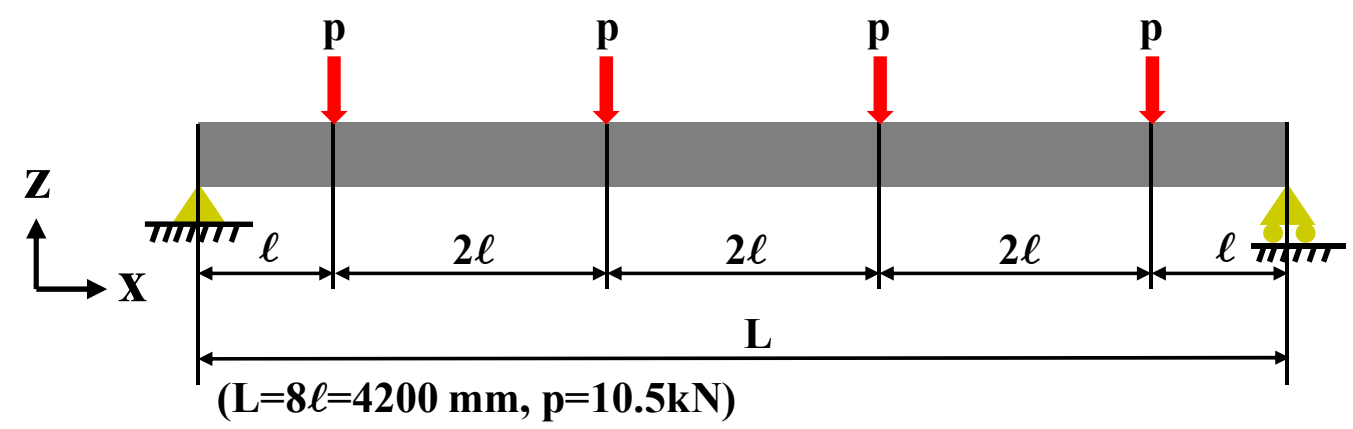

Fig. 6. Target I-girder in test (Cong et al., 2005) and validation of modelling technique (Pail et al., 2013). 


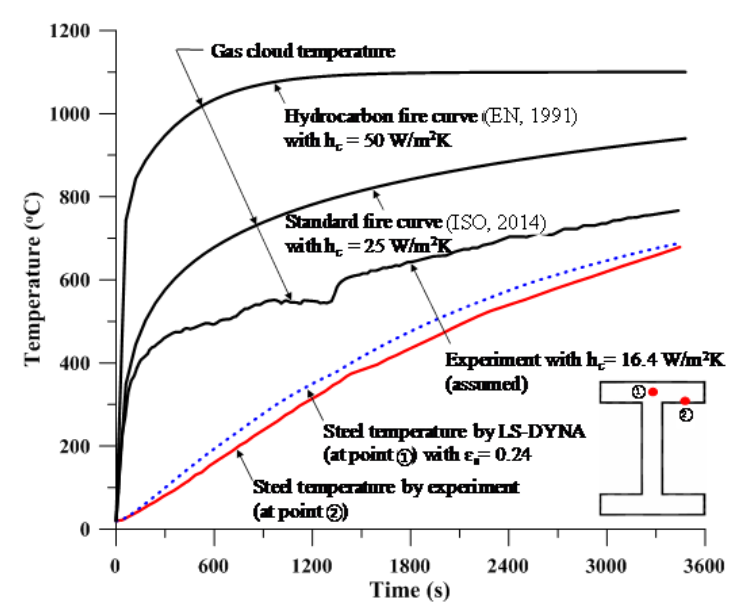

(a) At center of upper flange

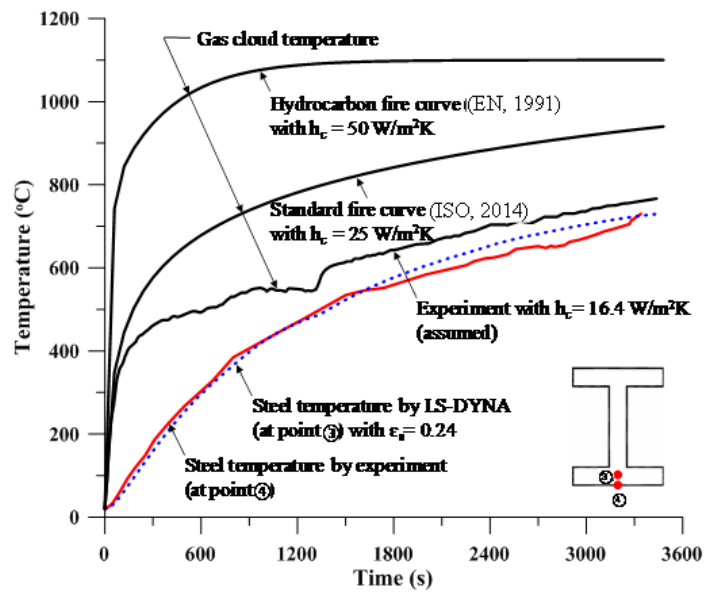

(b) At center of lower flange

Fig. 7. Comparison of steel temperature at the mid-section of beam (Paik et al., 2013).

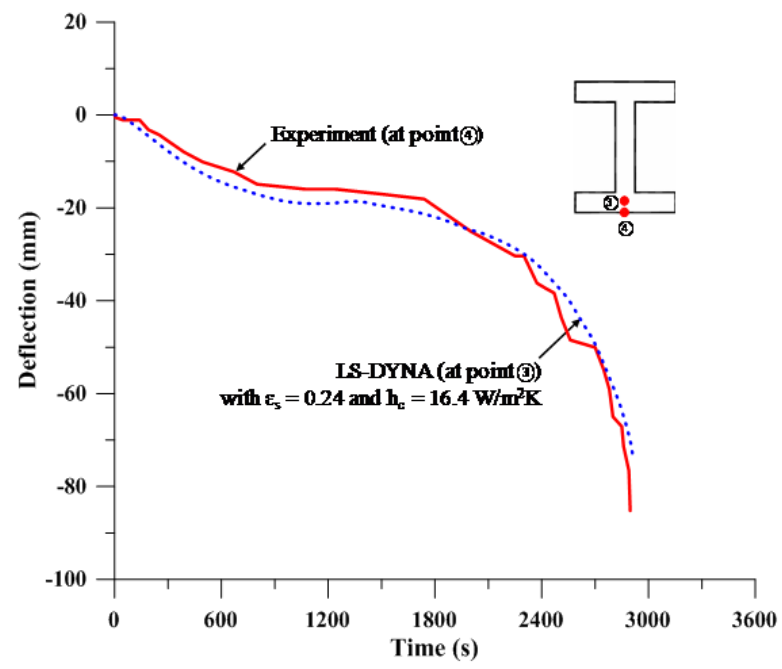

Fig. 8. Comparison of structural response at the mid-section of beam (Paik et al., 2013).
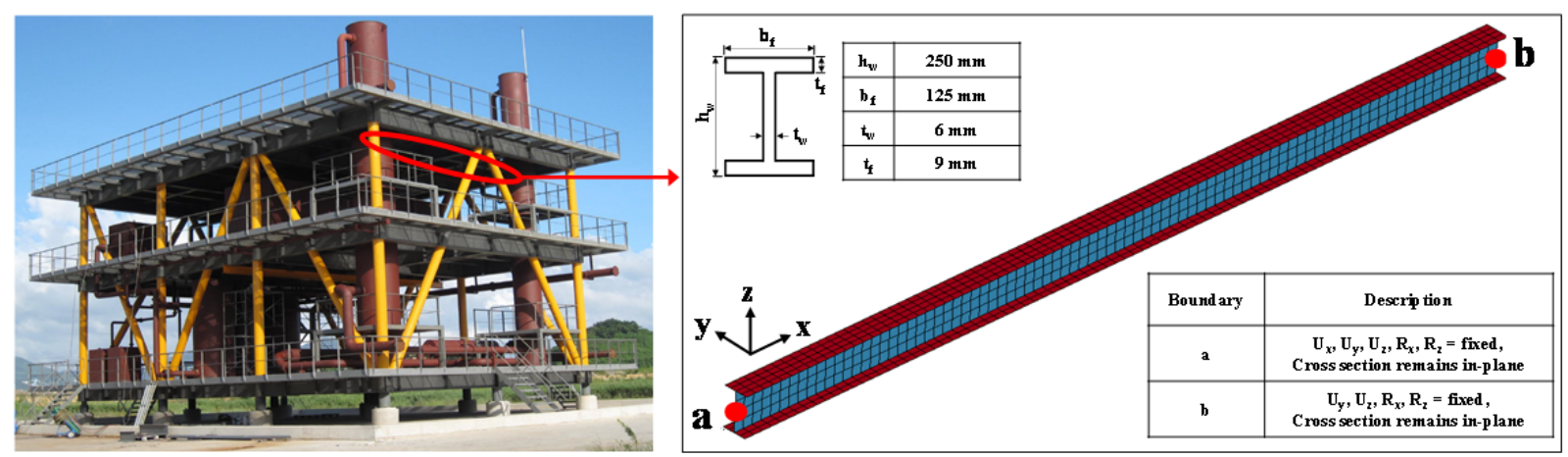

Fig. 9. Target structure for two-way FSI analysis and applied boundary conditions. 


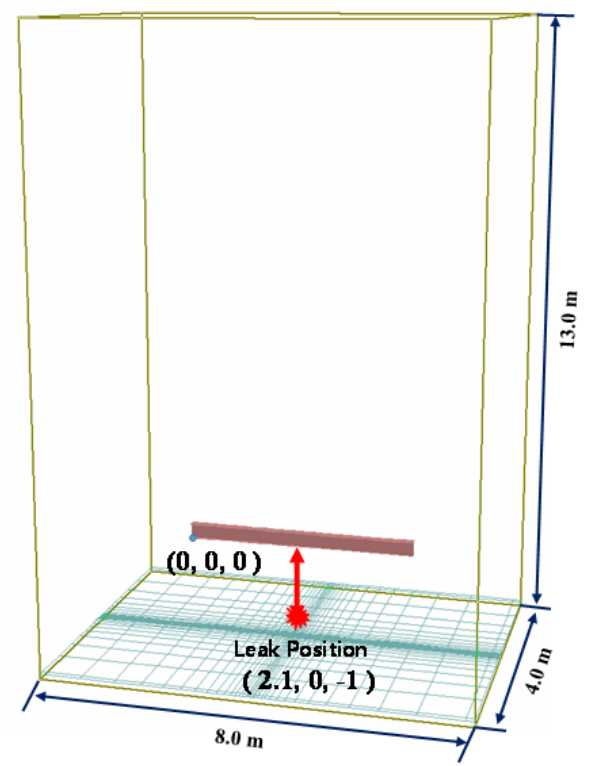

Fig. 10. Extent of analysis for the jet fire CFD simulation in KFX.

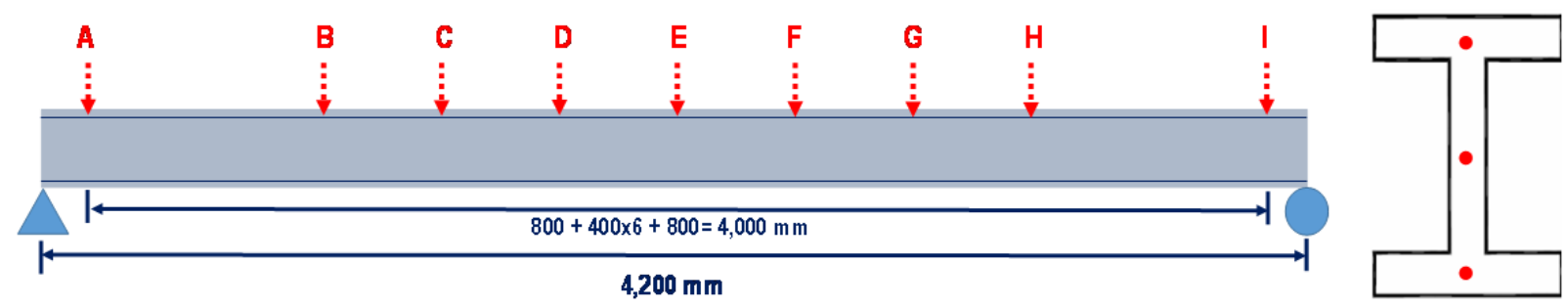

Fig. 11. Location of sections and monitoring points for obtaining results including temperatures and structural response.

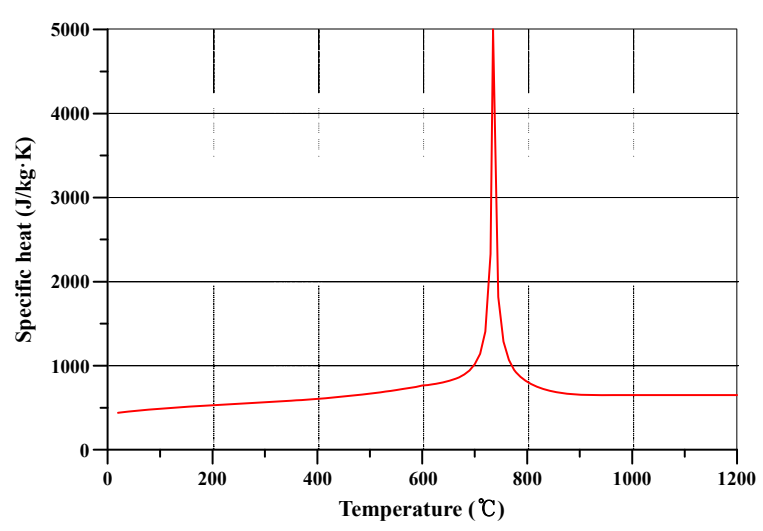

(a) Specific heat

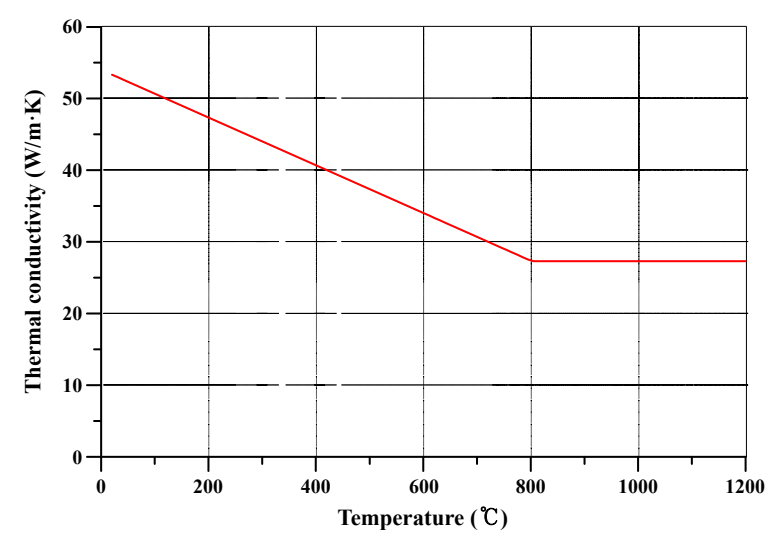

(b) Thermal conductivity

Fig. 12. Change of material properties of carbon steel as a function of the temperature (EN, 2005). 


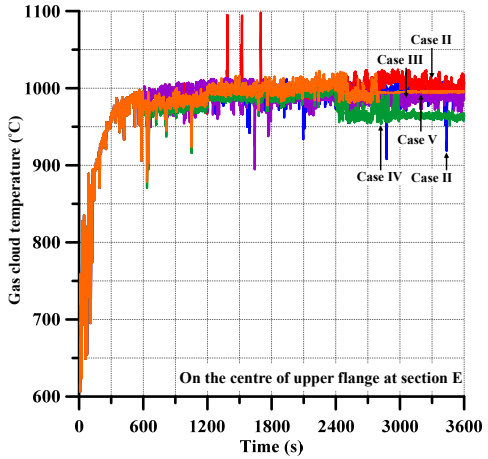

(a) At center of upper flange

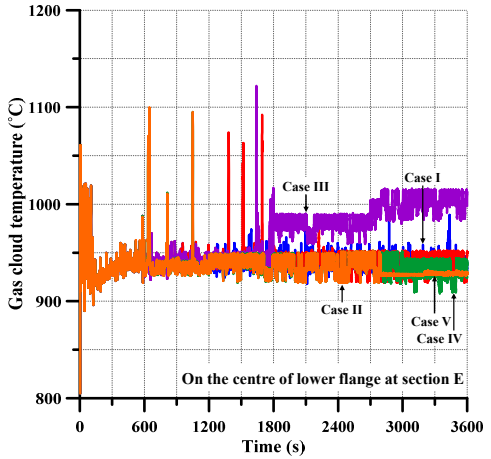

(b) At center of lower flange

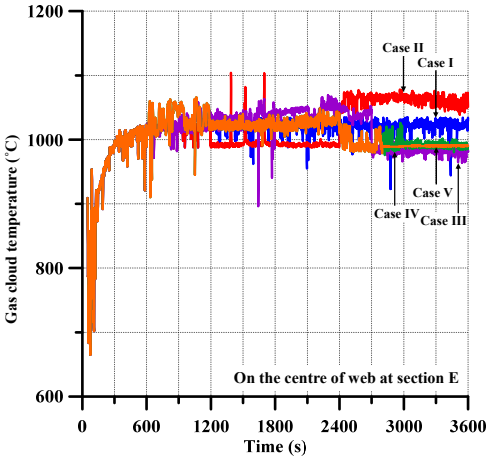

(c) At center of web

Fig. 13. Gas cloud temperature-time histories at section E, as given by FSI analysis (CFD simulation).

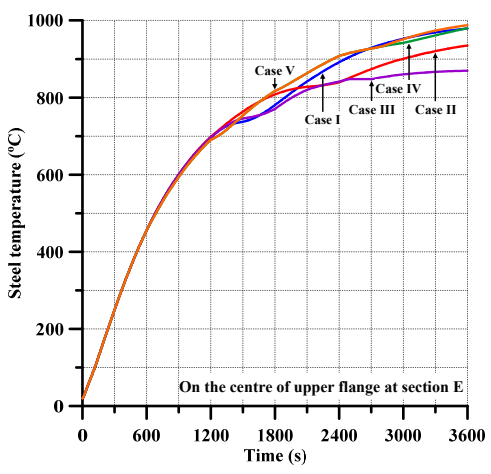

(a) At center of upper flange

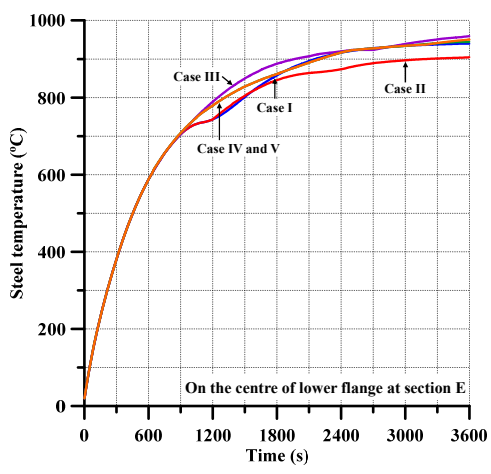

(b) At center of lower flange

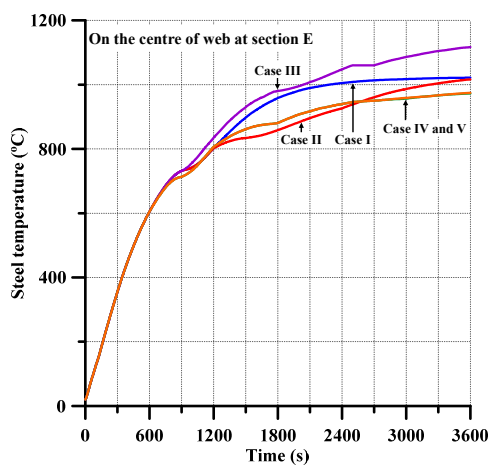

(c) At center of web

Fig. 14. Steel temperature-time histories at section E, as given by FSI analysis (heat transfer analysis).

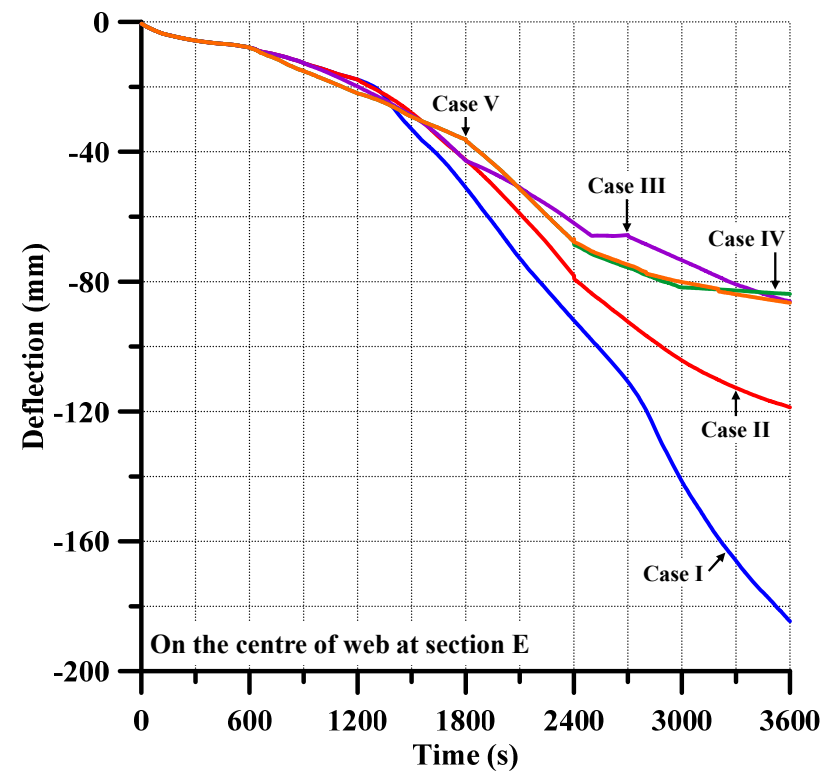

Fig. 15. Deflection-time histories at the center of the web on section E, according to FSI analysis (nonlinear FEA). 


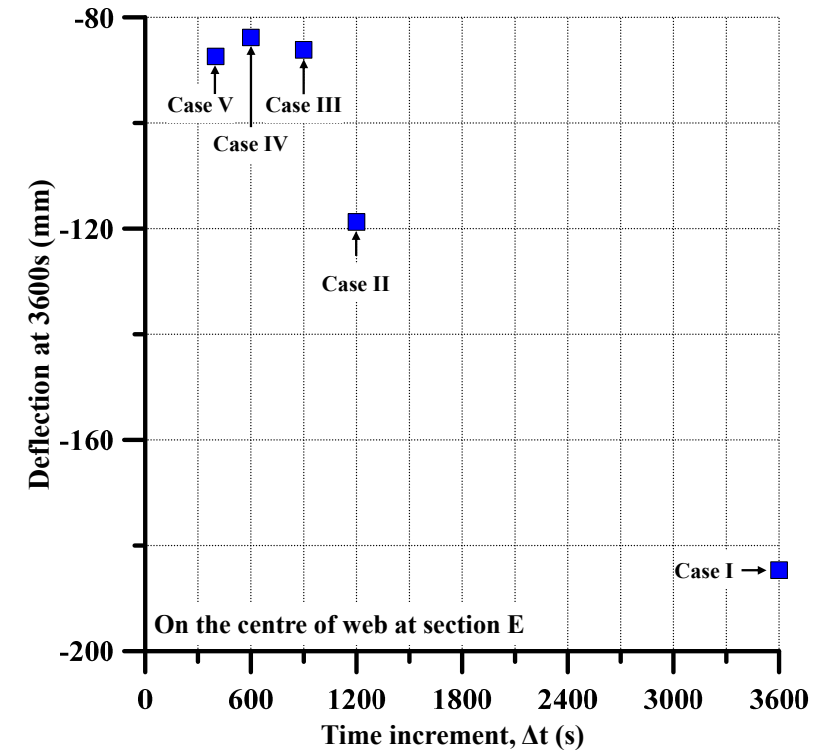

Fig. 16. Maximum deflection versus time increments in the FSI analysis.

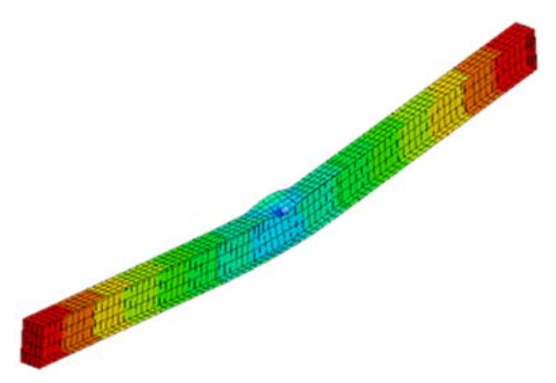

(a) Case I

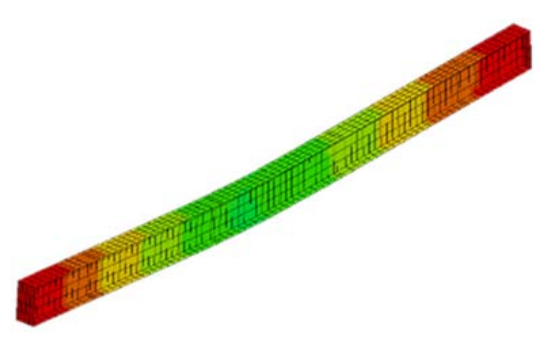

(b) Case II

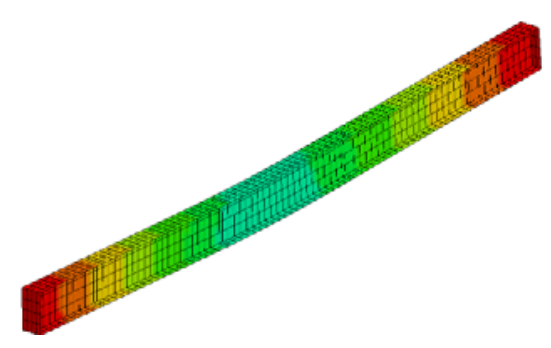

(c) Case III

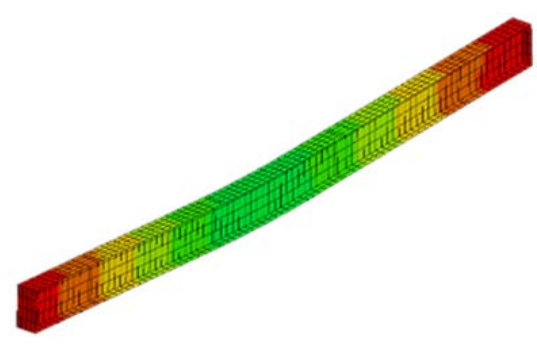

(d) Case IV

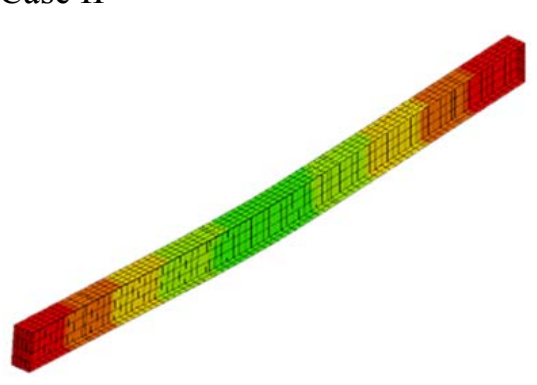

(e) Case V

Fig. 17. Deformed shape, as projected by nonlinear structural analysis at $3600 \mathrm{~s}$. 


\section{Appendix A. Results of FSI analysis of I-girder subjected to jet fire}
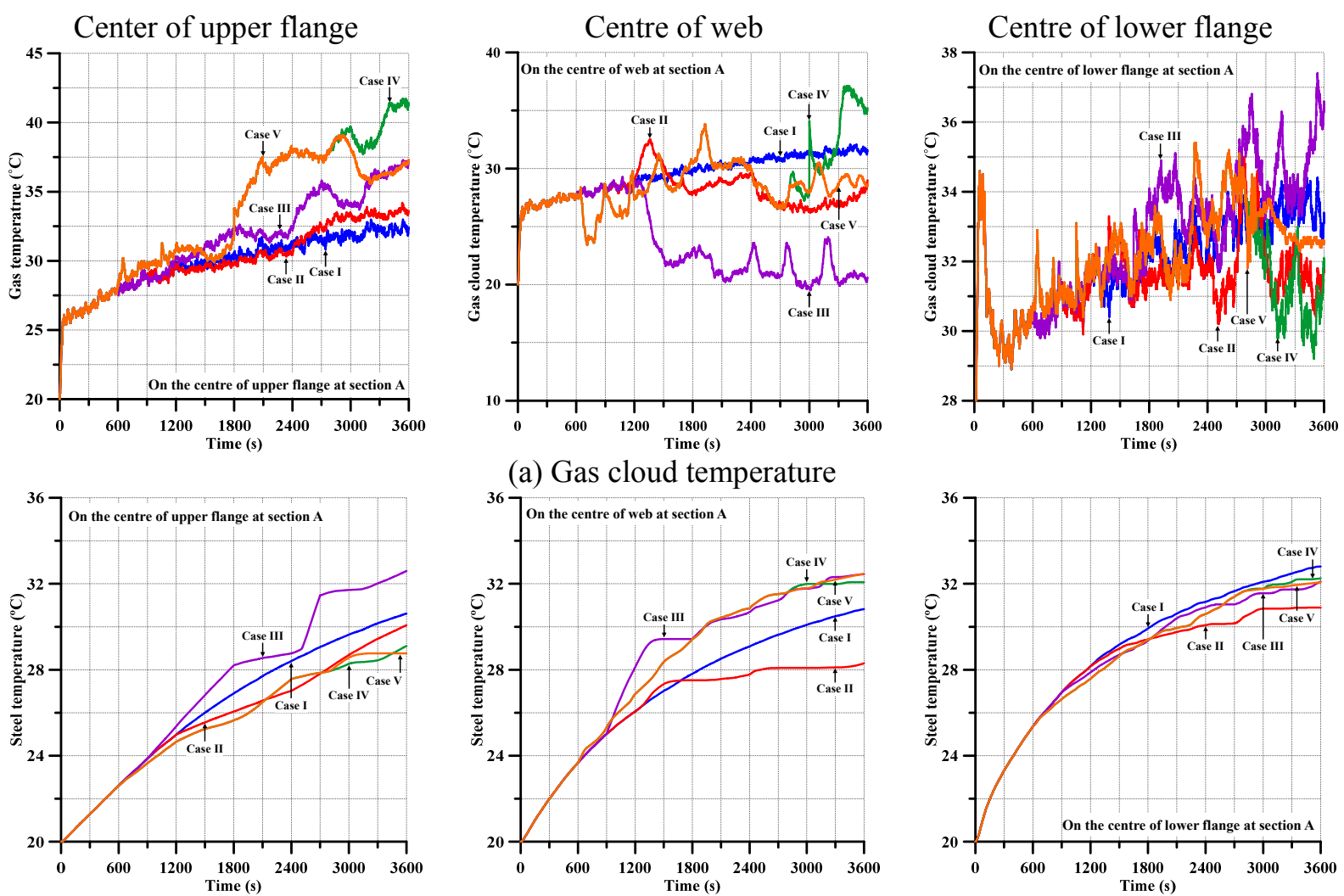

(a) Gas cloud temperature
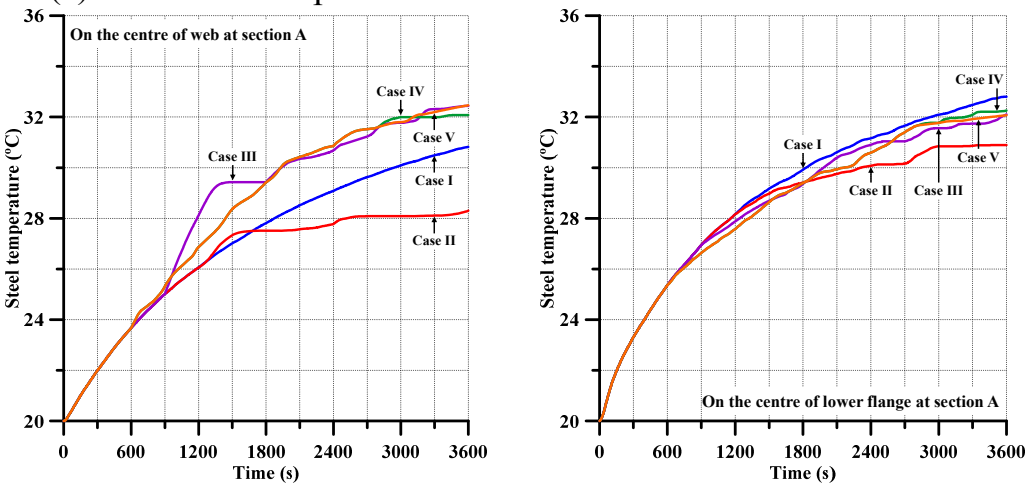

(b) Steel temperature

Fig. A.1. Temperature-time histories at section A by FSI analysis.

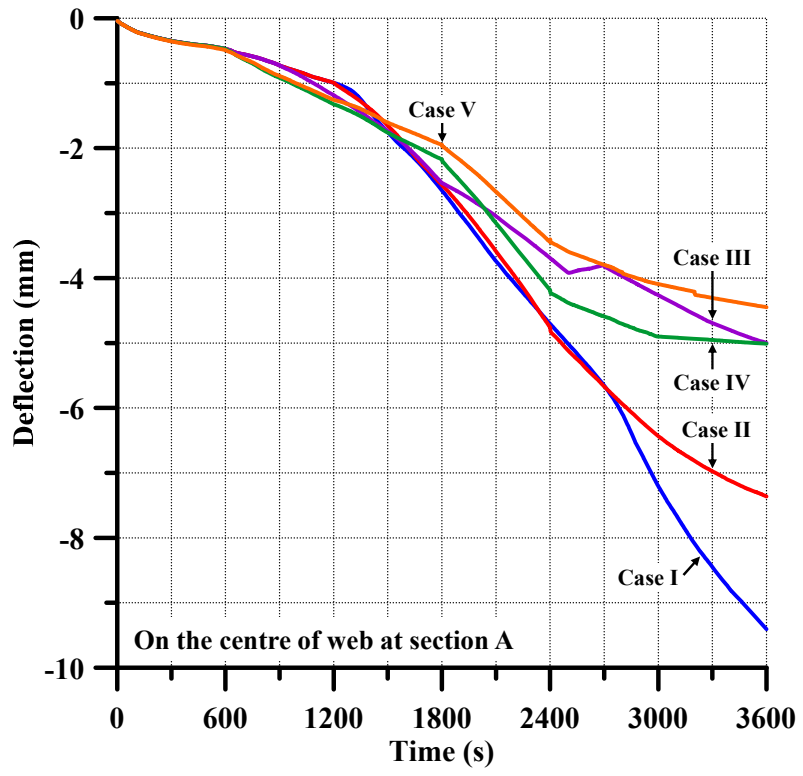

Fig. A.2. Deflection-time histories at center of section A by FSI analysis. 

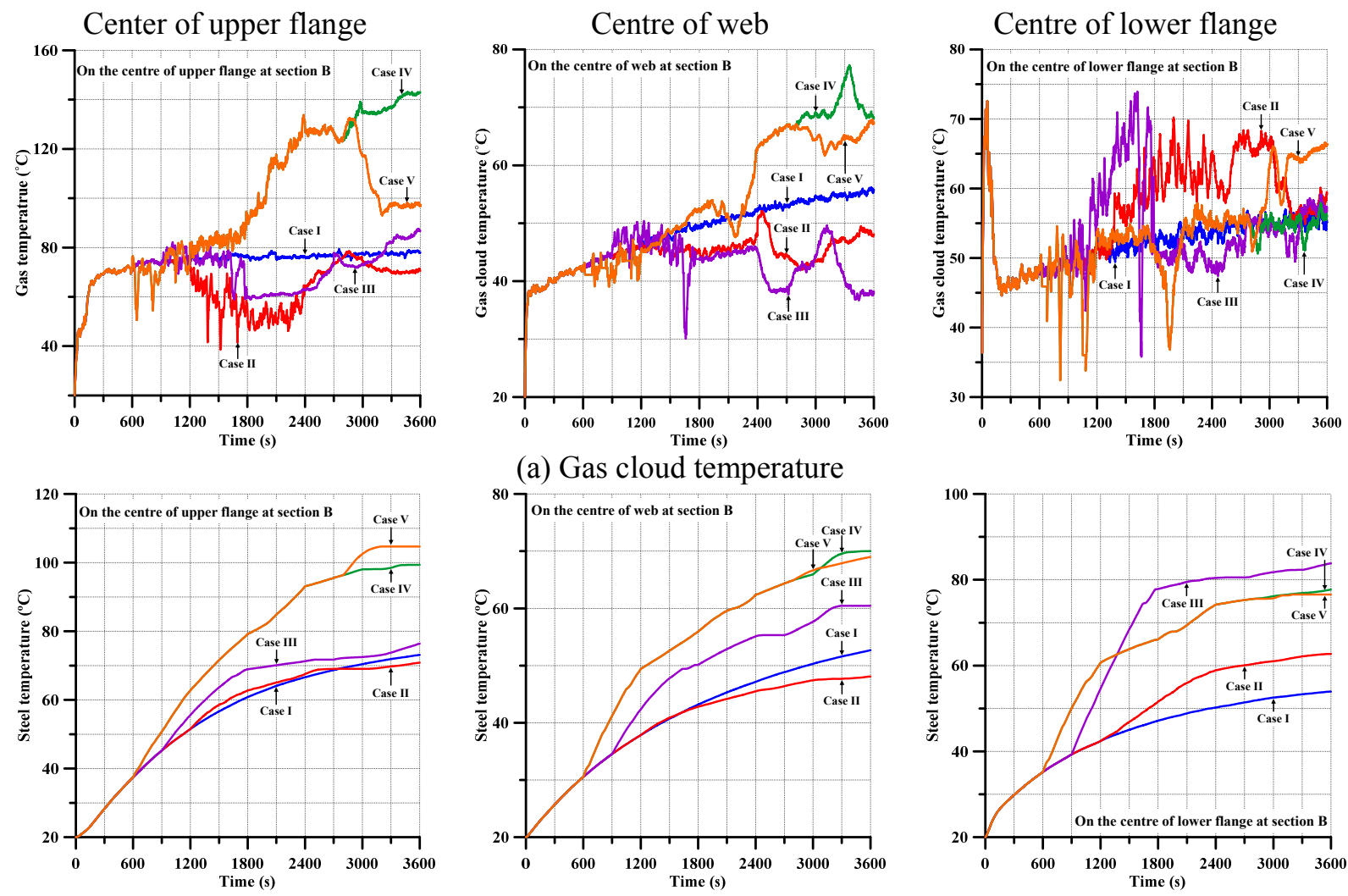

(a) Gas cloud temperature
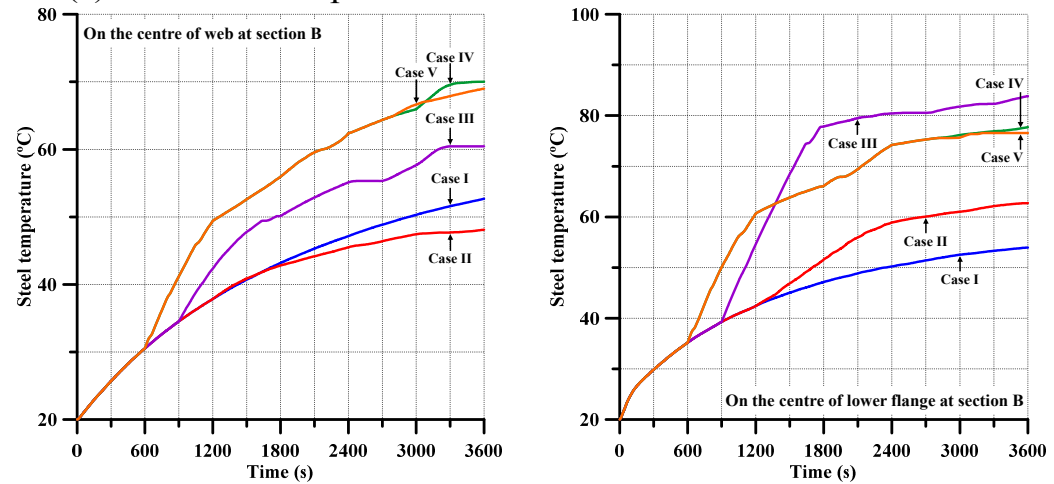

(b) Steel temperature

Fig. A.3. Temperature-time histories at section B by FSI analysis.

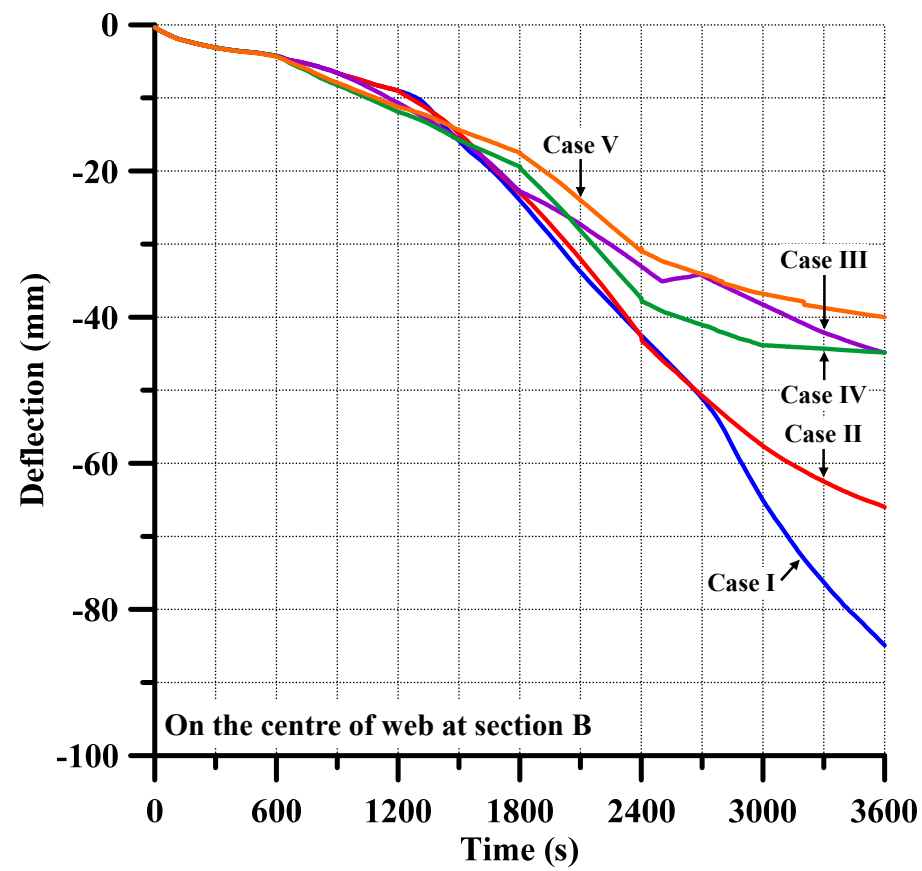

Fig. A.4. Deflection-time histories at center of section B by FSI analysis. 

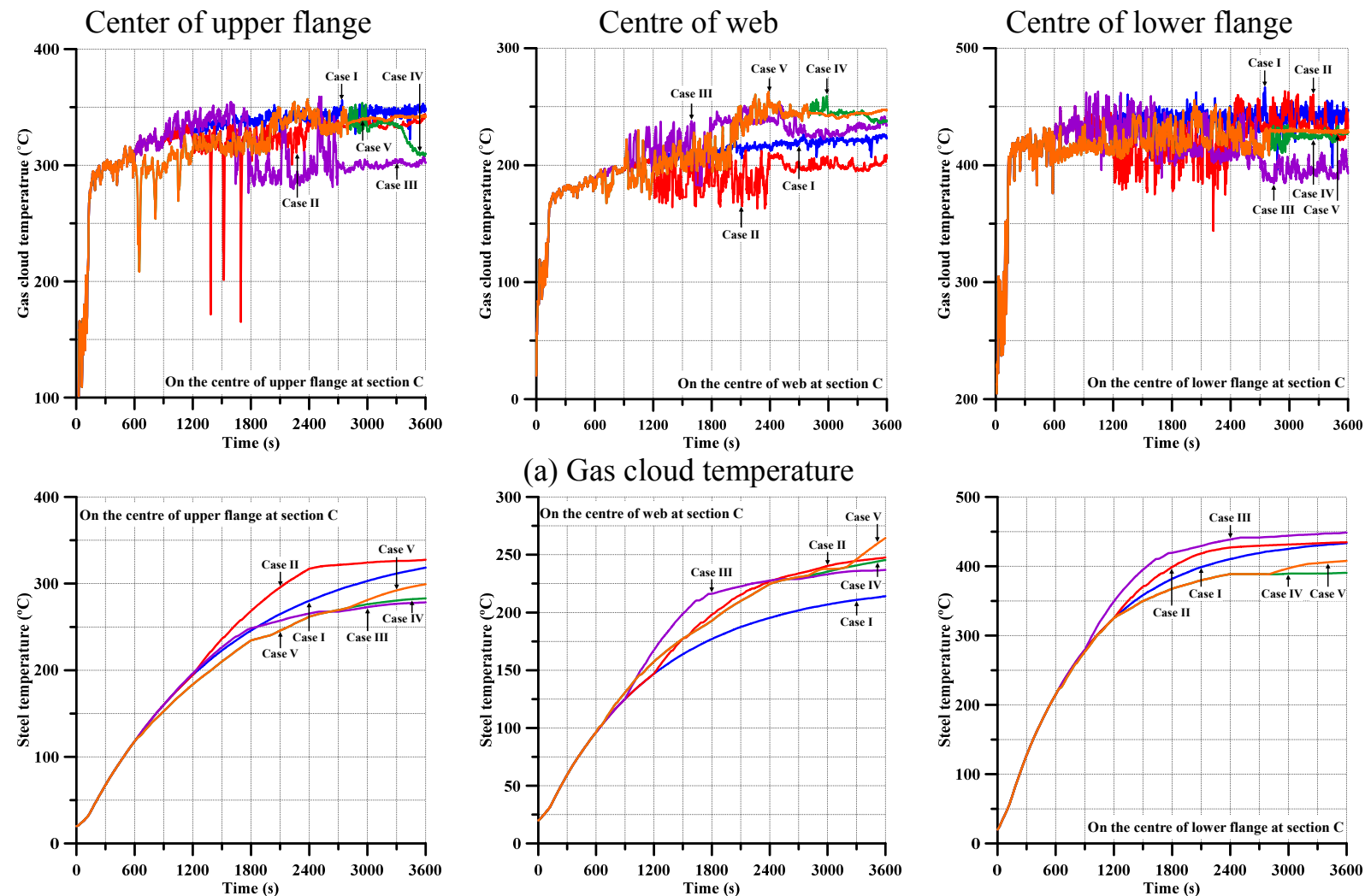

(a) Gas cloud temperature
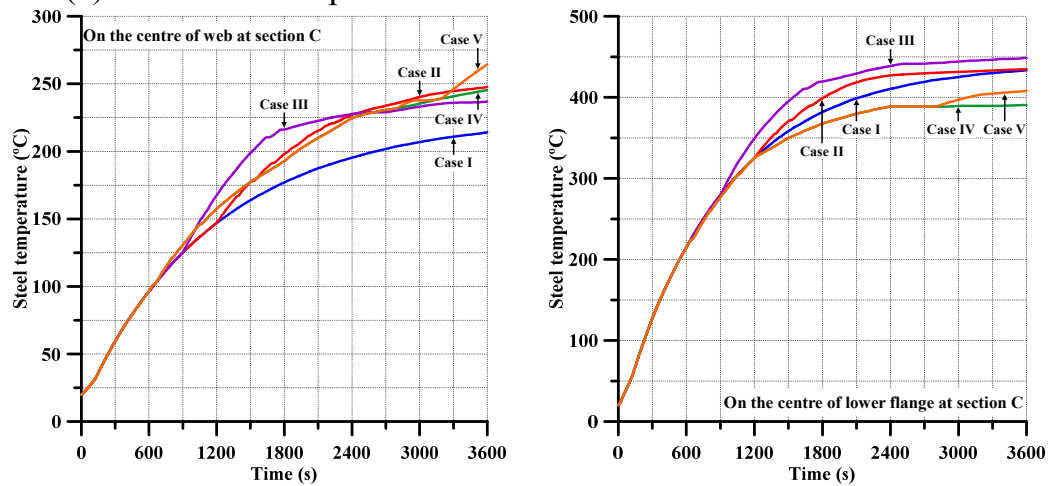

(b) Steel temperature

Fig. A.5. Temperature-time histories at section C by FSI analysis.

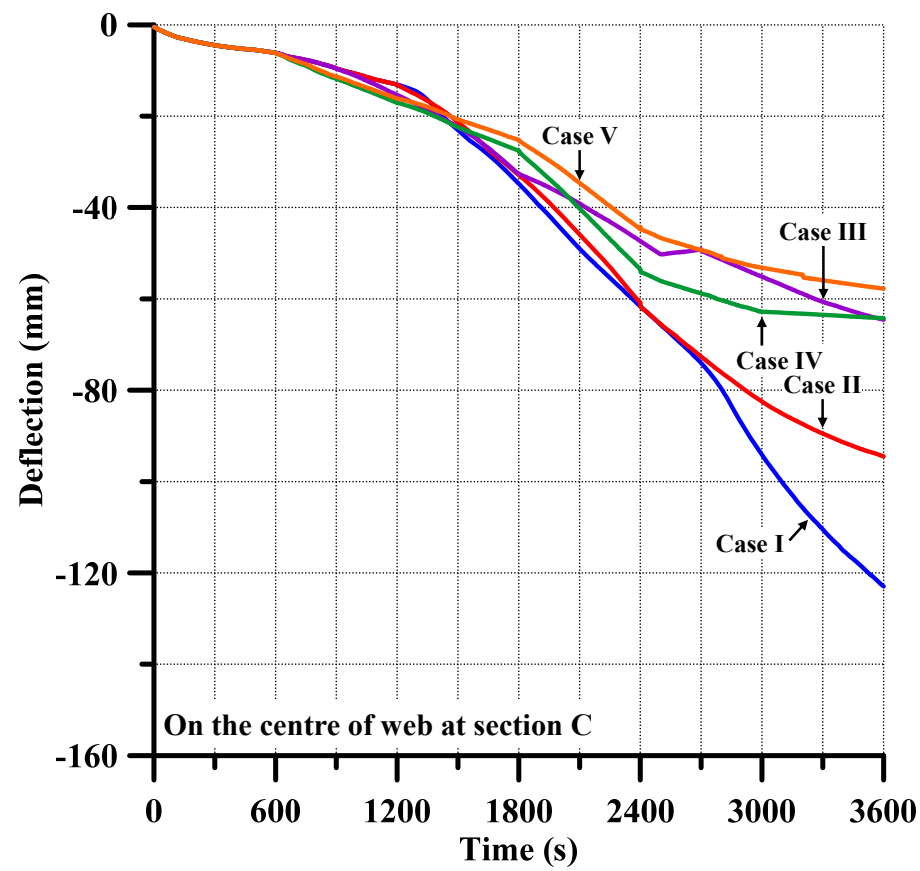

Fig. A.6. Deflection-time histories at center of section C by FSI analysis. 

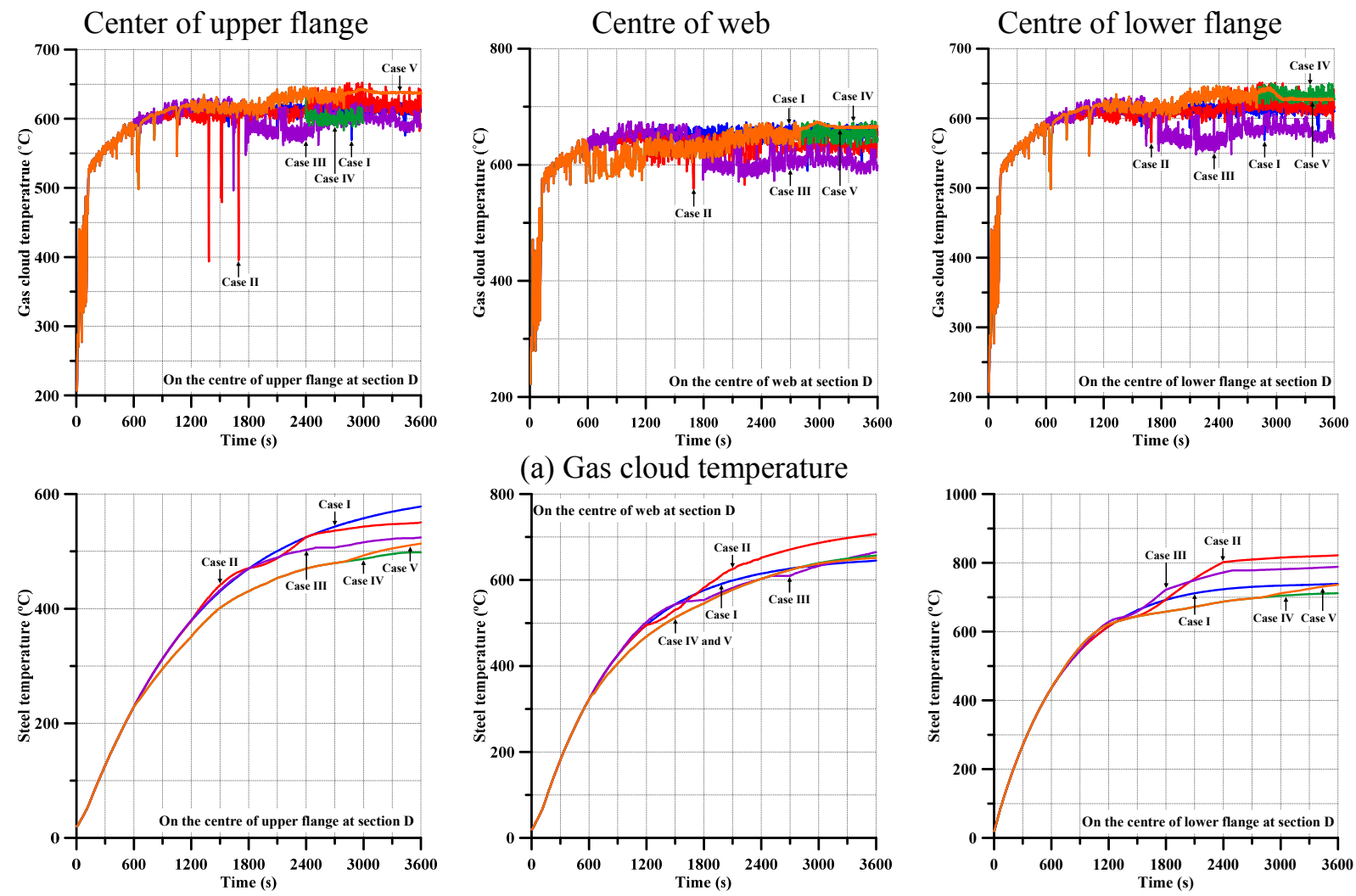

(a) Gas cloud temperature
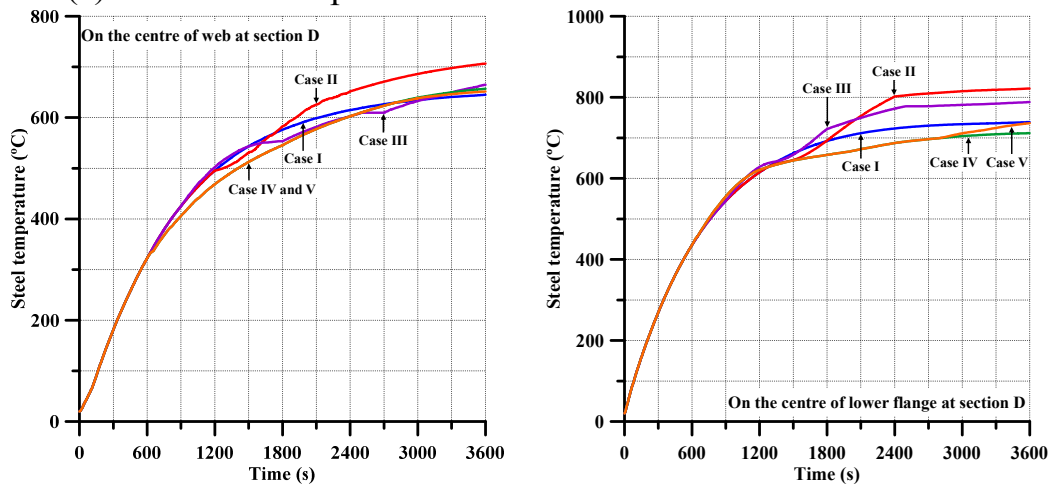

(b) Steel temperature

Fig. A.7. Temperature-time histories at section D by FSI analysis.

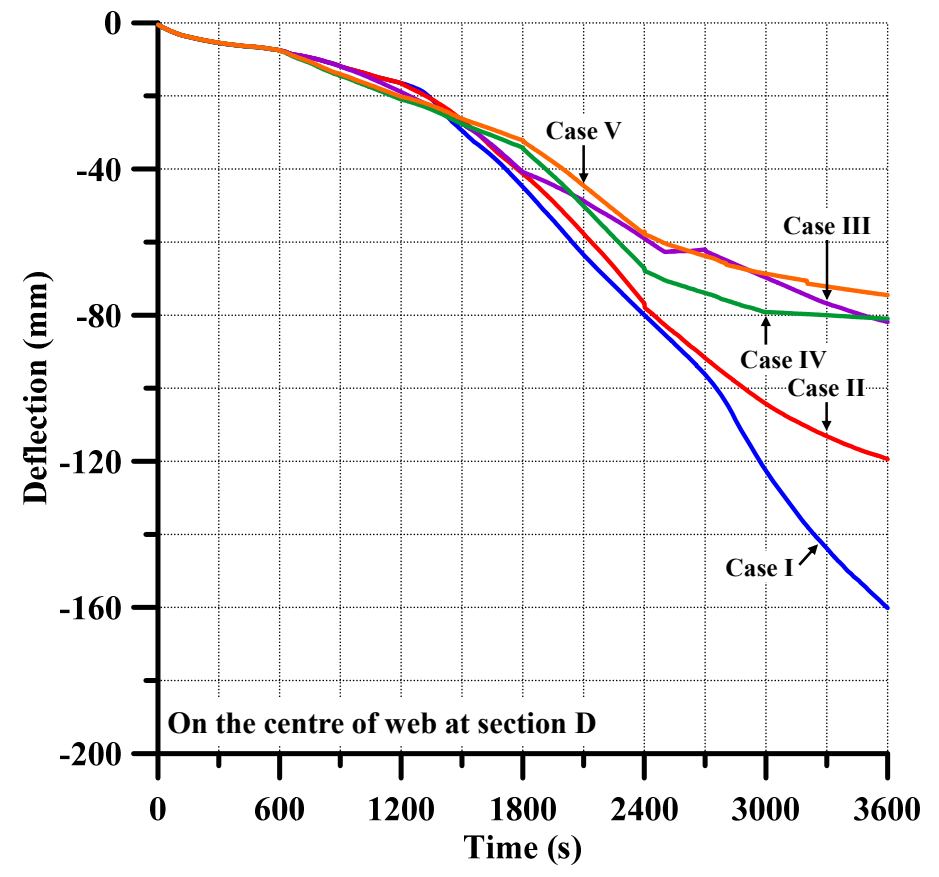

Fig. A.9. Deflection-time histories at center of section D by FSI analysis. 

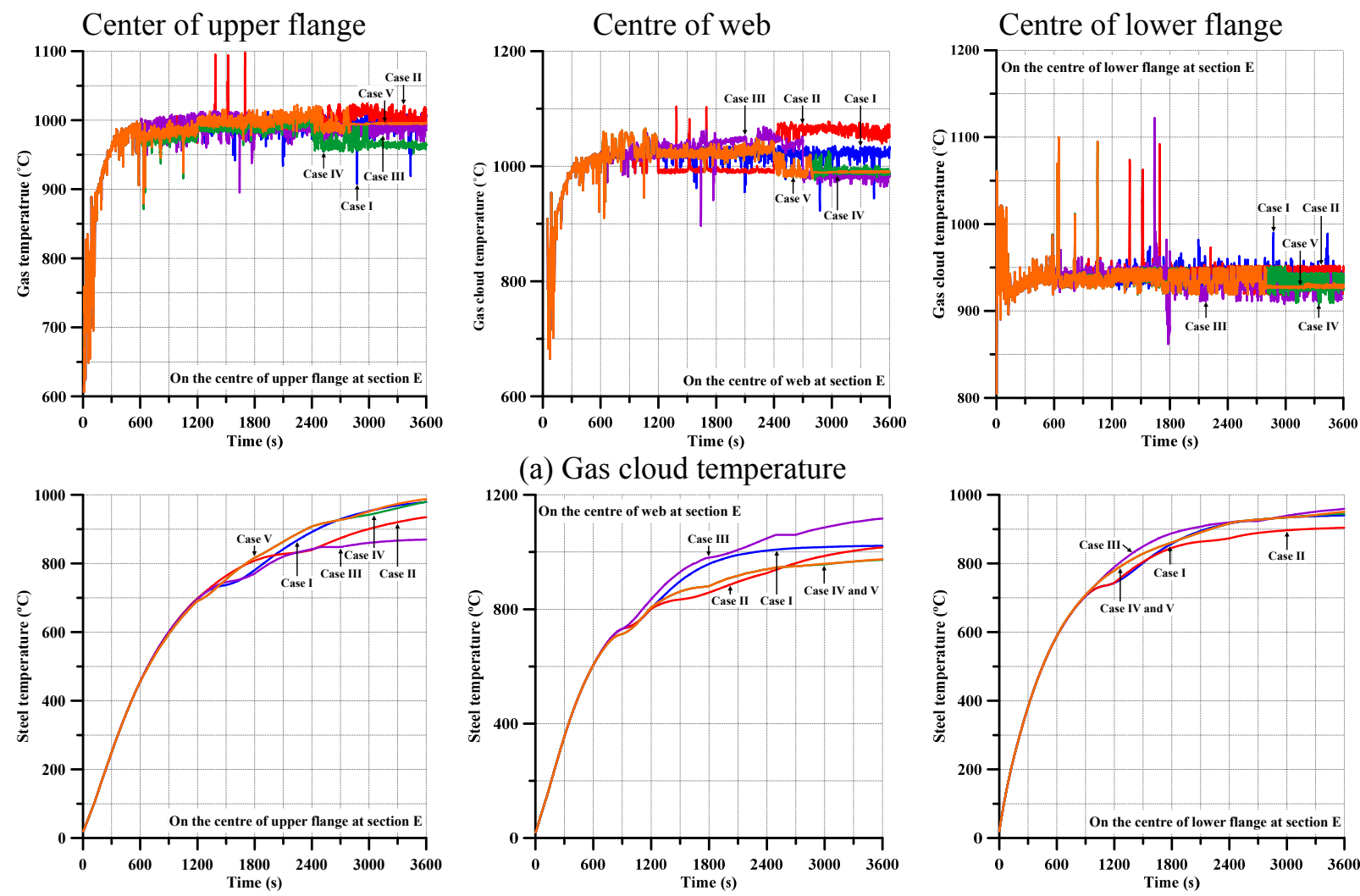

(a) Gas cloud temperature
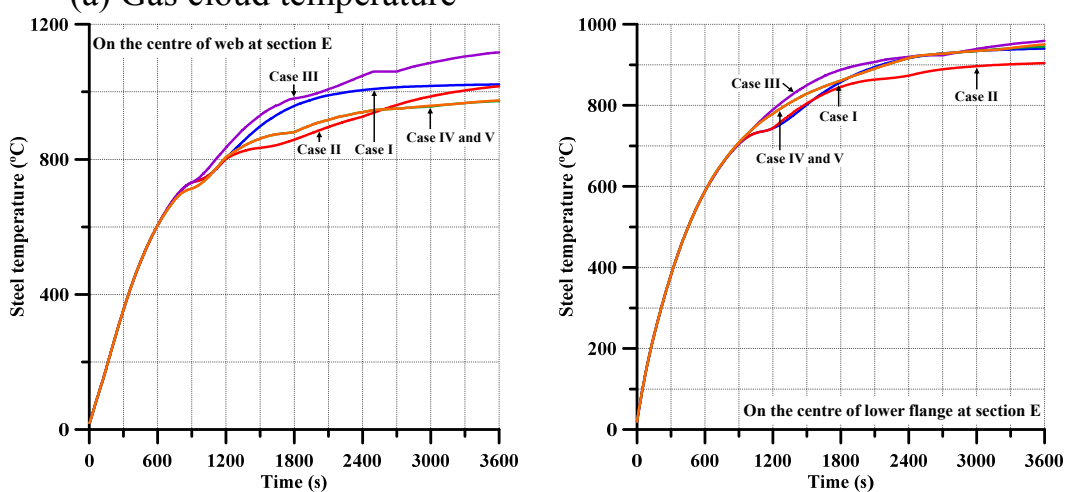

(b) Steel temperature

Fig. A.9. Temperature-time histories at section E by FSI analysis.

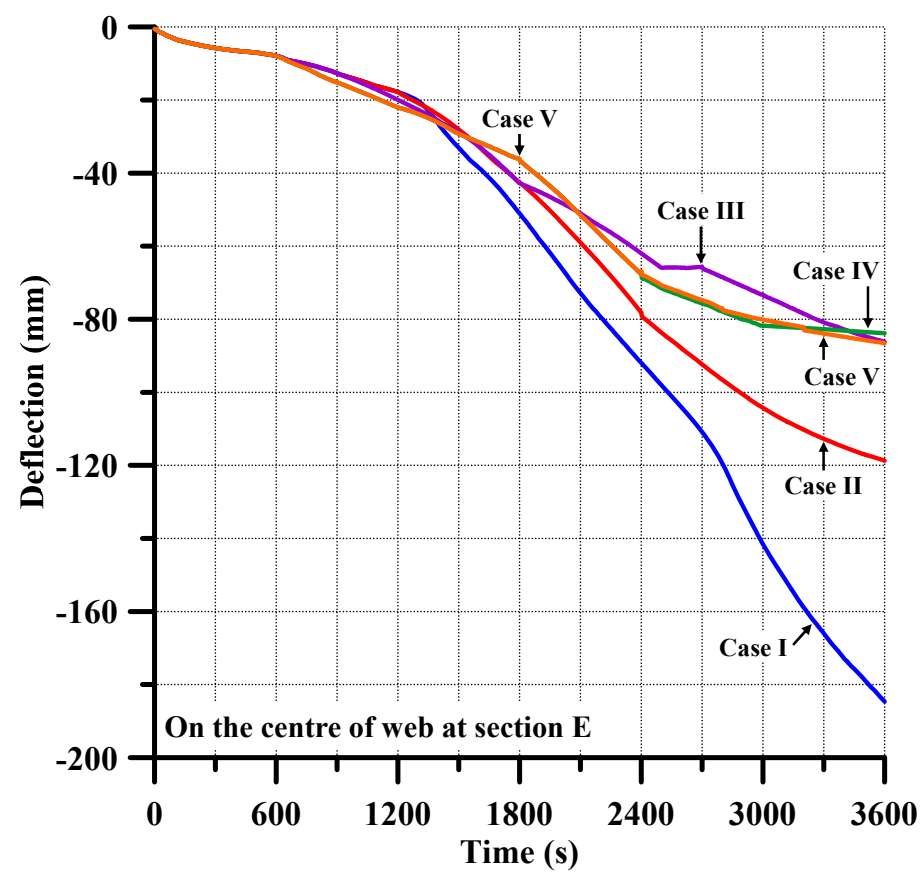

Fig. A.10. Deflection-time histories at center of section E by FSI analysis. 

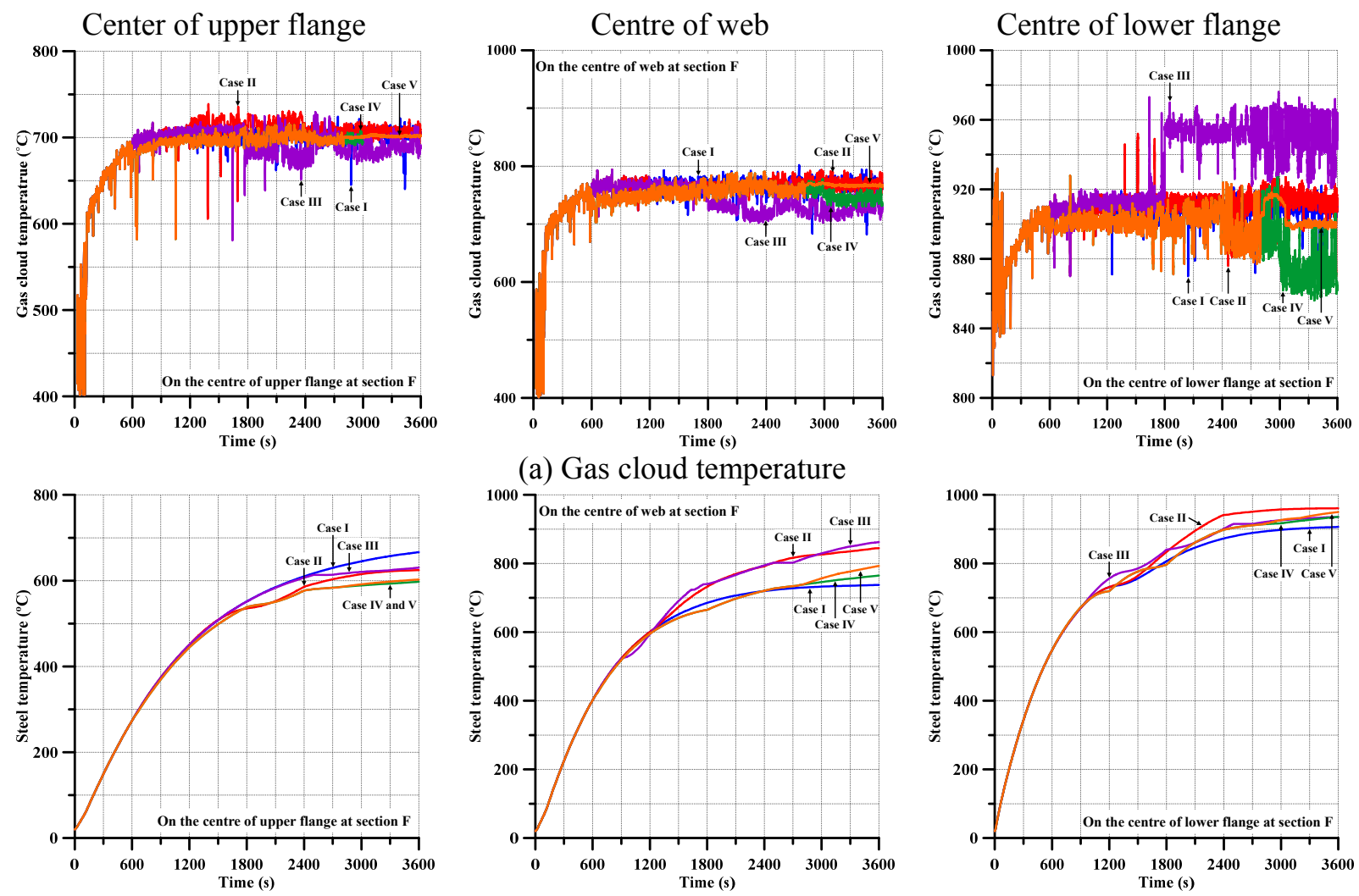

(a) Gas cloud temperature
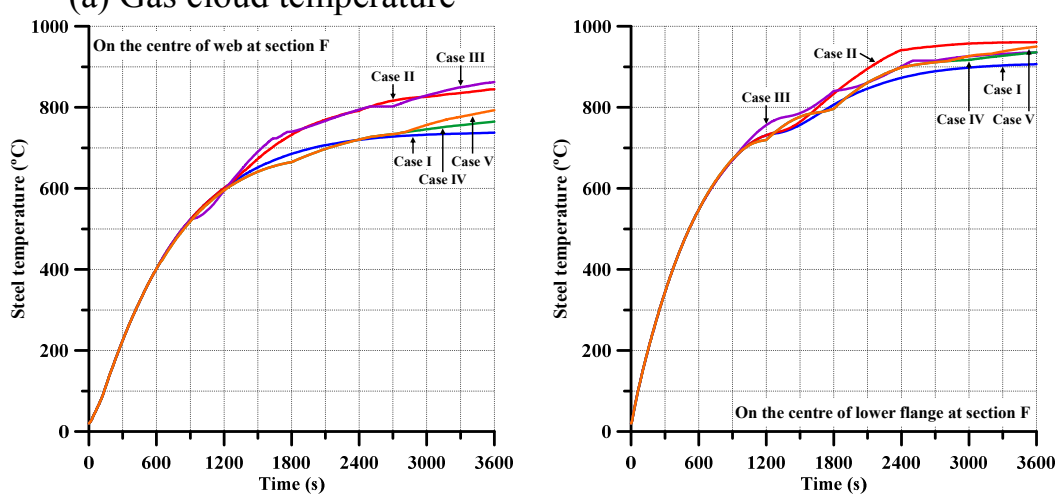

(b) Steel temperature

Fig. A.11. Temperature-time histories at section F by FSI analysis.

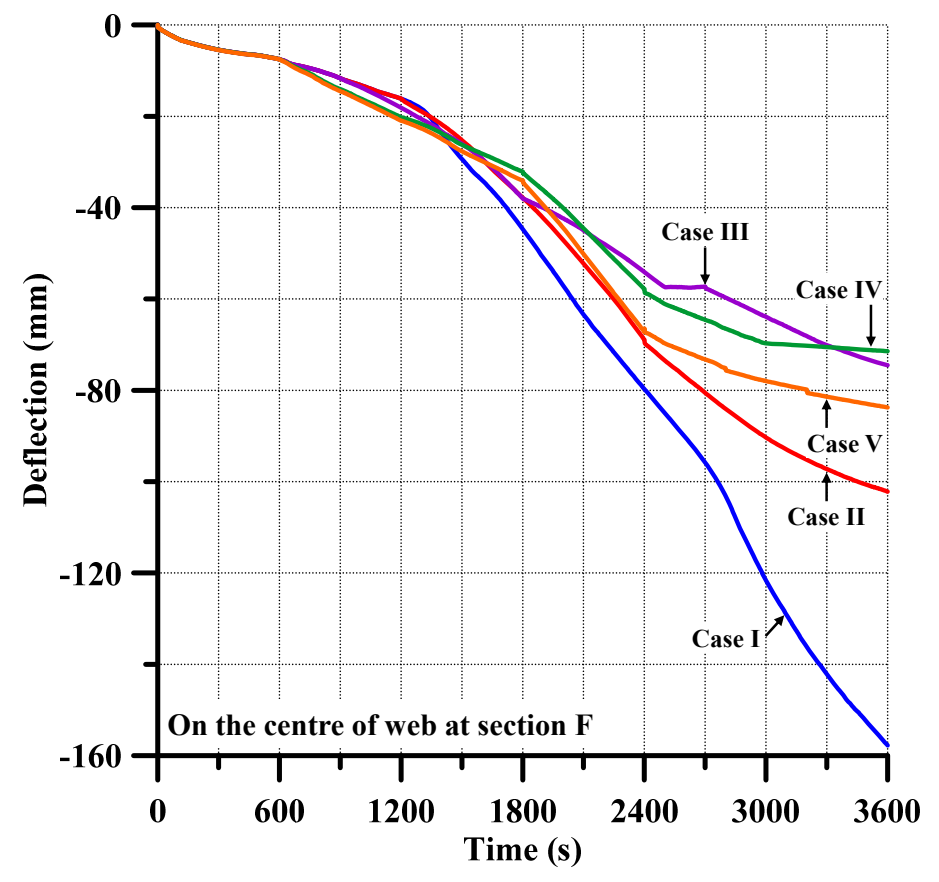

Fig. A.12. Deflection-time histories at center of section F by FSI analysis. 

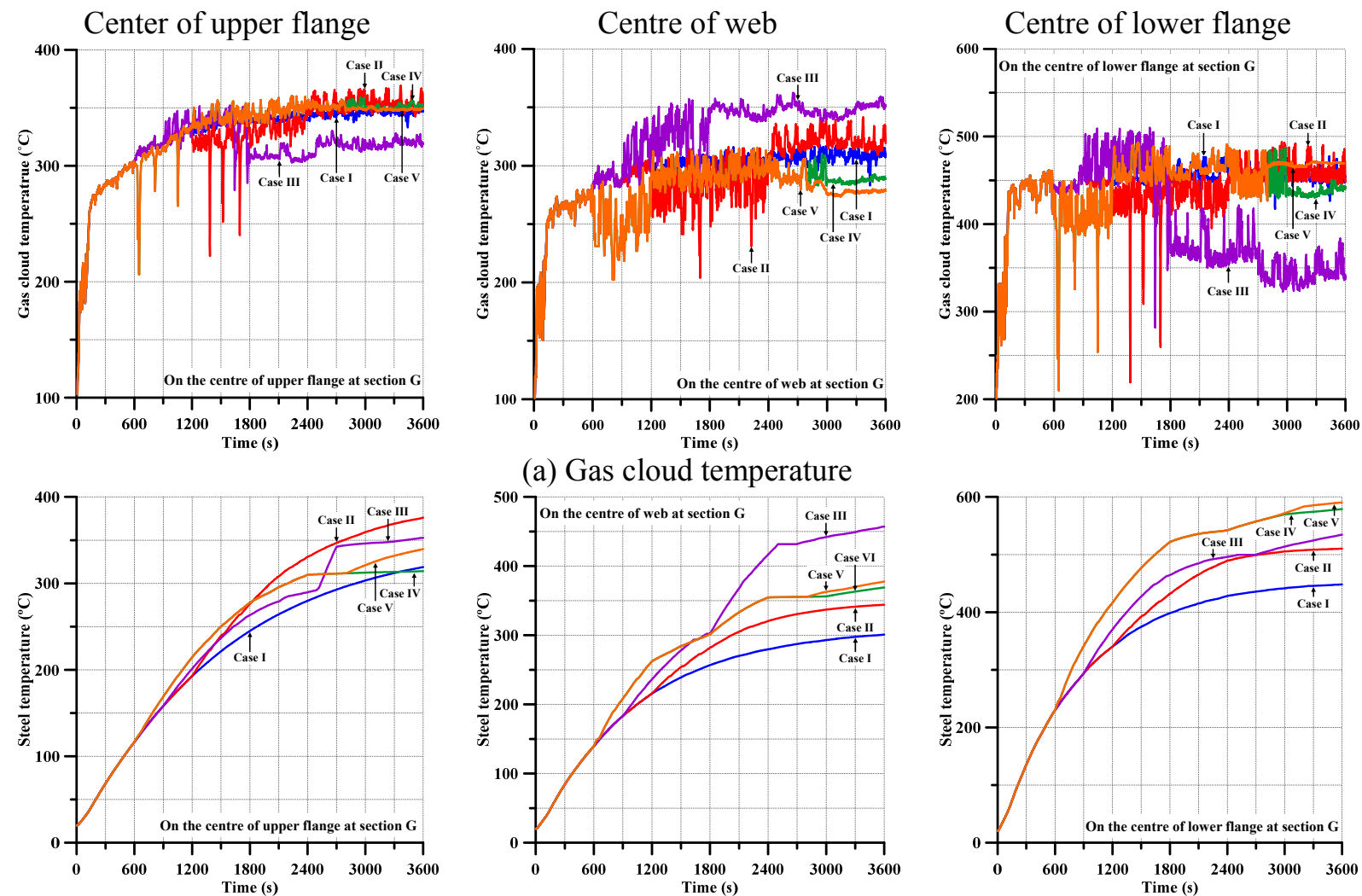

(a) Gas cloud temperature
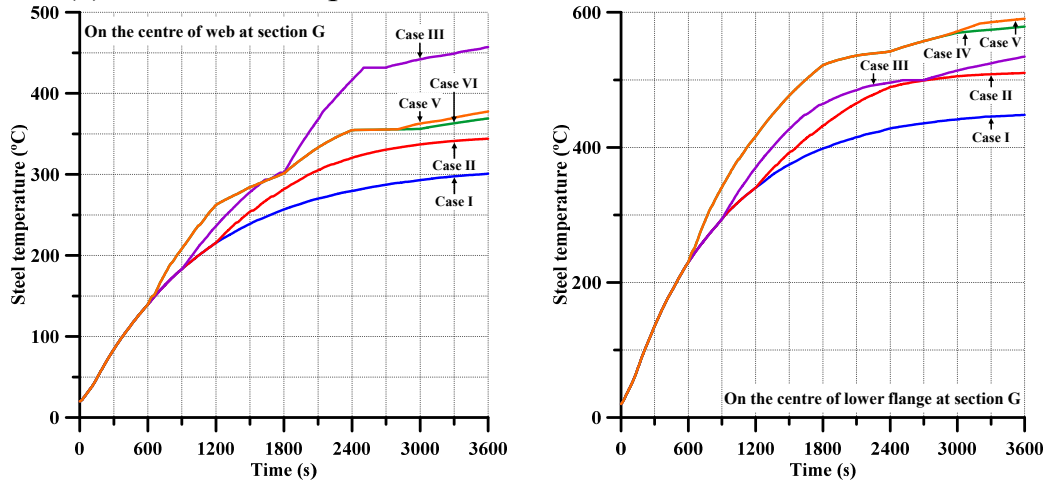

(b) Steel temperature

Fig. A.13. Temperature-time histories at section G by FSI analysis.

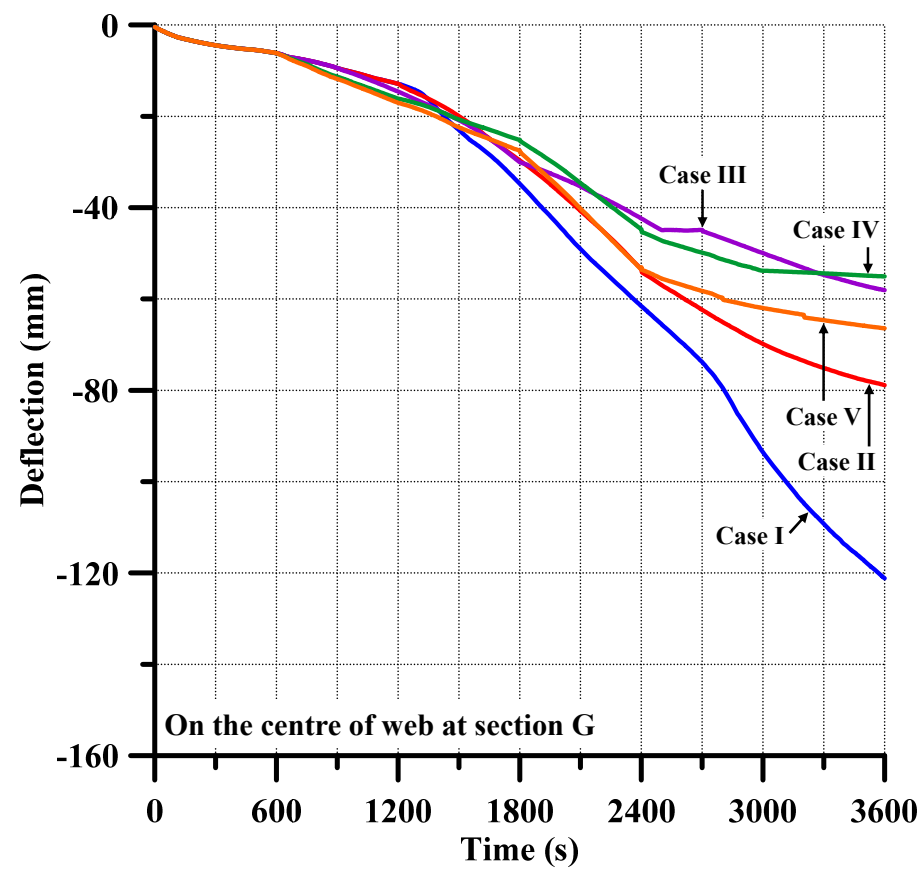

Fig. A.14. Deflection-time histories at center of section G by FSI analysis. 

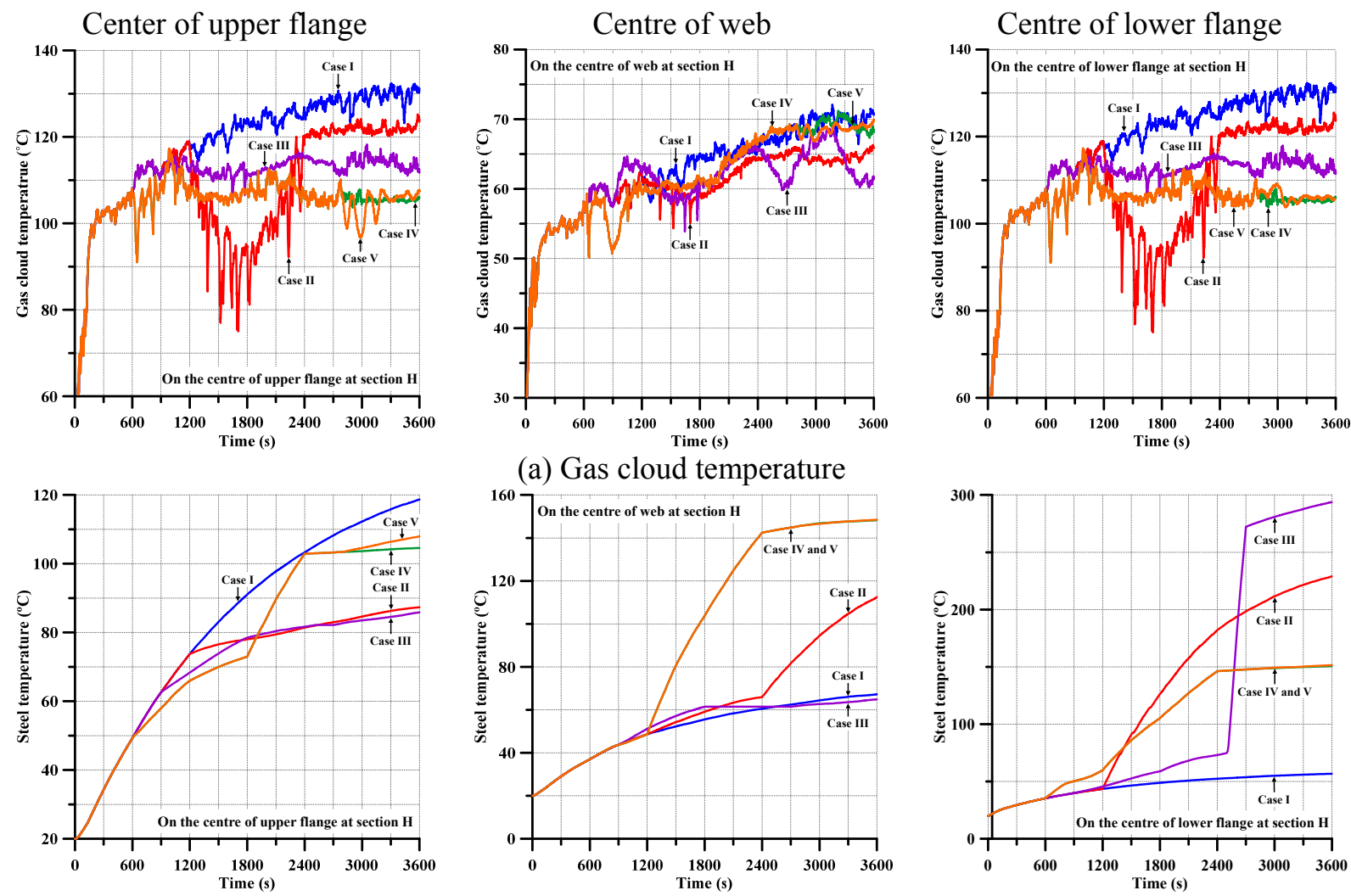

(a) Gas cloud temperature
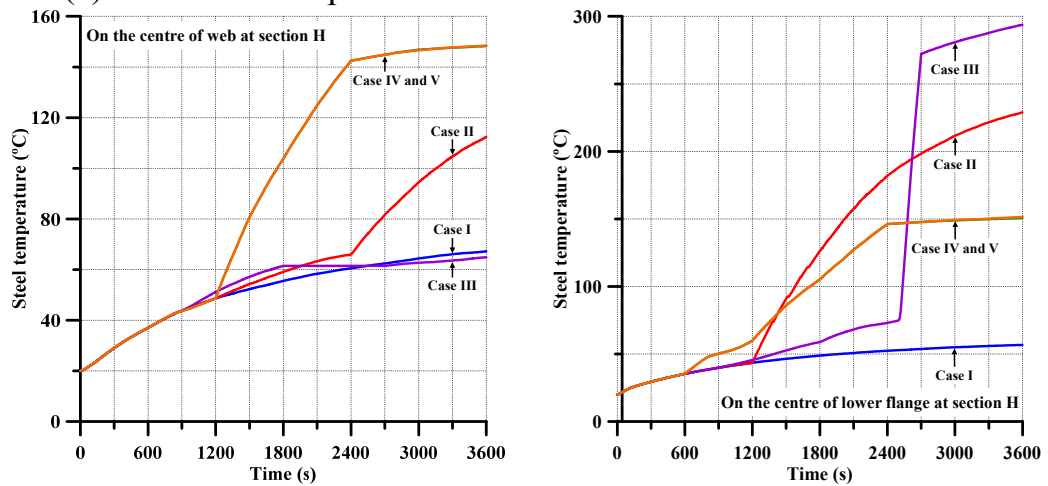

(b) Steel temperature

Fig. A.15. Temperature-time histories at section H by FSI analysis.

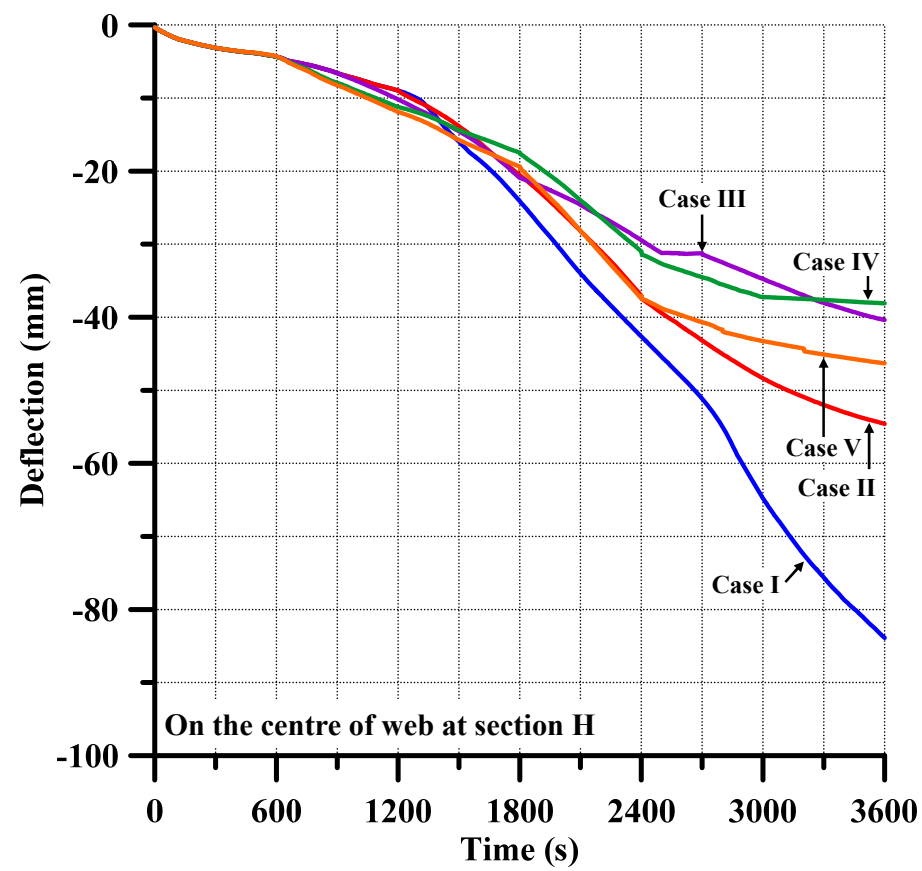

Fig. A.16. Deflection-time histories at center of section H by FSI analysis. 

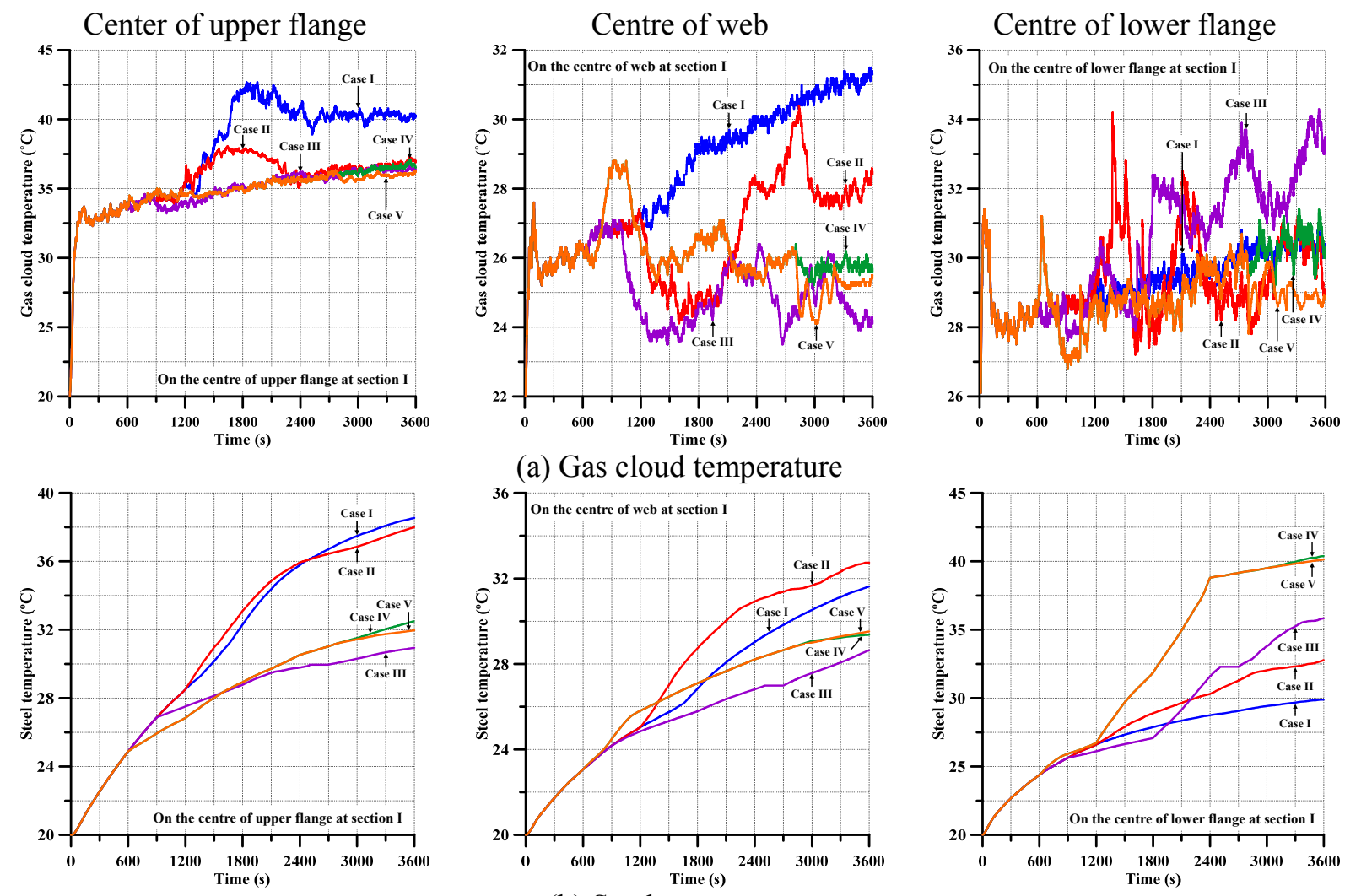

(a) Gas cloud temperature
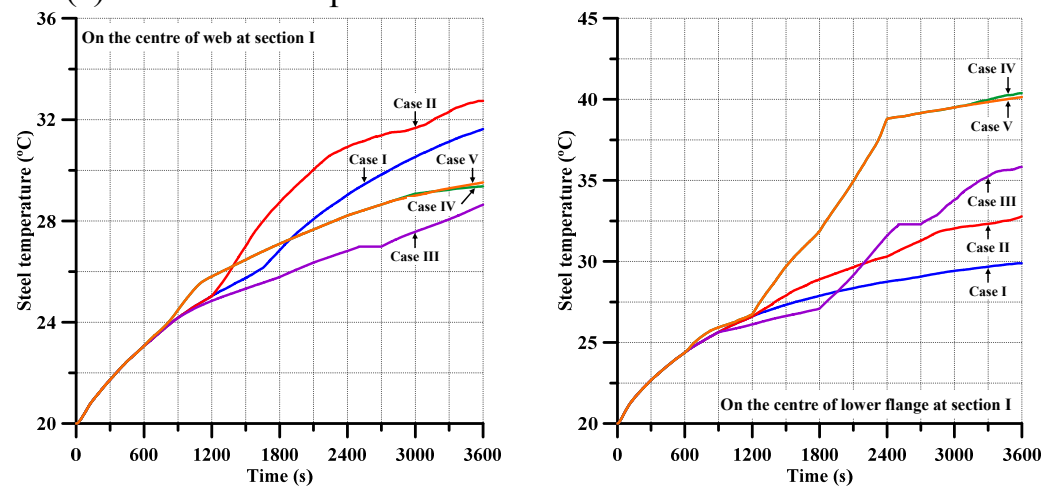

(b) Steel temperature

Fig. A.17. Temperature-time histories at section I by FSI analysis.

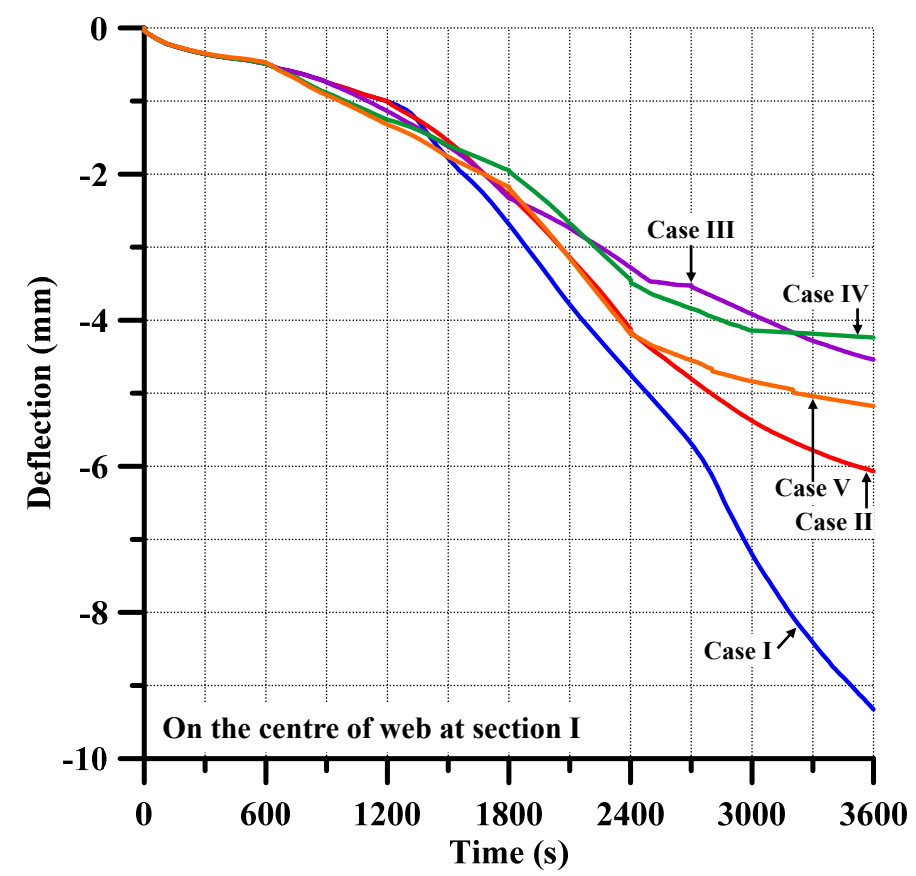

Fig. A.18. Deflection-time histories at center of section I by FSI analysis. 